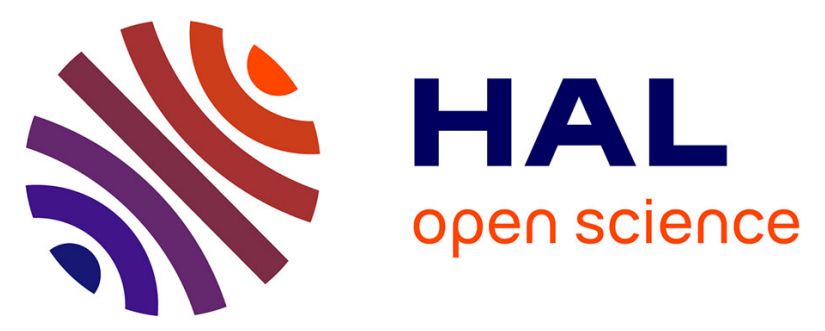

\title{
Iron and Copper Nanoparticles Inside and Outside Carbon Nanotubes: Nanoconfinement, Migration, Interaction and Catalytic Performance in Fischer-Tropsch Synthesis
}

Ana Katiuce Fellenberg, Ahmed Addad, Jingping Hong, Pardis Simon, Yuliia Kosto, Břetislav Šmíd, G Ji, Andrei y Khodakov

\section{To cite this version:}

Ana Katiuce Fellenberg, Ahmed Addad, Jingping Hong, Pardis Simon, Yuliia Kosto, et al.. Iron and Copper Nanoparticles Inside and Outside Carbon Nanotubes: Nanoconfinement, Migration, Interaction and Catalytic Performance in Fischer-Tropsch Synthesis. Journal of Catalysis, 2021, 10.1016/j.jcat.2021.09.034 . hal-03377536

\author{
HAL Id: hal-03377536 \\ https://hal.science/hal-03377536
}

Submitted on 14 Oct 2021

HAL is a multi-disciplinary open access archive for the deposit and dissemination of scientific research documents, whether they are published or not. The documents may come from teaching and research institutions in France or abroad, or from public or private research centers.
L'archive ouverte pluridisciplinaire HAL, est destinée au dépôt et à la diffusion de documents scientifiques de niveau recherche, publiés ou non, émanant des établissements d'enseignement et de recherche français ou étrangers, des laboratoires publics ou privés. 
Iron and Copper Nanoparticles Inside and Outside Carbon Nanotubes: Nanoconfinement, Migration, Interaction and Catalytic Performance in FischerTropsch Synthesis

Ana Katiuce Fellenberg ${ }^{a, b}$, Ahmed Addad $^{b}$, Jingping Hong ${ }^{c}$, Pardis Simon ${ }^{a}$, Yuliia Kosto ${ }^{d}$, Břetislav Šmíd ${ }^{d}$ Gang $\mathrm{Ji}^{b^{*}}$ and Andrei Y. Khodakov ${ }^{a^{*}}$

${ }^{a}$ University of Lille, CNRS, Centrale Lille, University of Artois, UMR 8181 - UCCS - Unité de Catalyse et Chimie du Solide, Lille, France

${ }^{b}$ University of Lille, CNRS, INRAE, Centrale Lille, UMR 8207 - UMET - Unité Matériaux et Transformations, F-59000, Lille, France

${ }^{c}$ Key Laboratory of Catalysis and Energy Materials Chemistry of Ministry of Education \& Hubei Key Laboratory of Catalysis and Materials Science, South-Central University for Nationalities, Wuhan 430074, China

${ }^{d}$ Department of Surface and Plasma Science, Faculty of Mathematics and Physics, Charles University, V Holešovičkách 747/2, 18000 Praha 8, Czechia

Corresponding authors: Dr Gang Ji (gang.ji@univ-lille.fr) and Dr Andrei Khodakov (andrei.khodakov@univ-lille.fr) 


\begin{abstract}
Carbon materials have attracted increasing attention as supports for metal catalysts. Ironcontaining carbon nanotubes often promoted with copper have found application in FischerTropsch synthesis, which provides an alternative way for conversion of renewable feedstocks to chemicals and fuels. In carbon nanotubes, the active phase can be nanoconfined inside the channels or localized on the outer surface. In most of previous work, the distribution of metal nanoparticles inside or outside carbon nanotubes is considered to be immobile during the catalyst activation or catalytic reaction.

In this paper, we uncovered remarkable mobility of both iron and copper species in the bimetallic catalysts between inner carbon nanotube channels and outer surface, which occurs in carbon monoxide and syngas, while almost no migration of iron species proceeds in the monometallic catalysts. This mobility is enhanced by noticeable fragility and defects in carbon nanotubes, which appear on their impregnation with the acid solutions of metal precursors and precursor decomposition. Remarkable mobility of iron and copper species in bimetallic catalysts affects the genesis of iron active sites, and enhances interaction of iron with the promoter. In the bimetallic iron-copper catalysts, the major increase in the activity was attributed to higher reaction turnover frequency over iron surface sites located in a close proximity with copper.
\end{abstract}

Keywords: nanoconfinement; syngas, Fischer-Tropsch; mobility, NAP-XPS; iron carbide; copper; promotion 


\section{Introduction}

In recent years, carbon materials have attracted increasing attention as supports for metal catalysts and demonstrated enhanced selectivity and activity for many reactions. Ironbased catalysts are the catalysts of choice for direct light olefin synthesis via hightemperature Fischer-Tropsch (FT) synthesis [1-3]. Iron catalysts show low selectivity to undesirable methane, high water-gas shift activity [4], which can adjust the low $\mathrm{H}_{2} / \mathrm{CO}$ ratio in syngas obtained from biomass or organic waste. The distribution of the FT synthesis hydrocarbons follows the broad Anderson-Schulz-Flory (ASF) distribution, which imposes a limitation on the selectivity to specific hydrocarbon fractions $[5,6]$.

Nanostructured carbon materials [7-9] seem to be suitable supports for iron FT catalysts, due to their unique nanostructures and properties: large surface area, good thermal and chemical stability, high thermal and electrical conductivity [5]. Furthermore, metal nanoparticles can be encapsulated inside carbon nanotubes (CNT). The encapsulation affects both the structure of the active phase and the mechanism of a chemical reaction and may result in several nanoconfinement effects. First, the size of iron encapsulated nanoparticles can be controlled by the CNT diameter [10]. The maximum size of metal nanoparticles inside CNT is limited by the nanotube walls. Second, the nanoparticles inside the CNT channels can adopt their shape [11] and morphology. Third, the encapsulation can prevent the nanoparticles from sintering during the catalyst activation and catalysis. Consequently, the iron spatial confinement [12] can minimize catalyst deactivation, resulting in the enhanced and stable catalytic performance. Four, the nanoconfinement can increase the concentration of the reagents inside the pores and thus affect the reaction rate. Five, the nanoconfinement of the active phase can affect the reaction mechanism. It can restrain [13] movement of 
reagents, intermediates and products via modification entropy and enthalpy of adsorbed reaction intermediates and transition states. Finally, the electronic properties of nanoparticles can be affected by nanoconfinement. The group of Bao [14-16] showed that the redox properties of encapsulated iron species and their catalytic performance in FT synthesis were modified by nanoconfinement. The conventional approach considers that nanoconfinement can be achieved during the catalyst synthesis, when the active component has been introduced to the support. It has been usually considered in the literature that the subsequent history of the catalyst which involves calcination, activation and catalytic reaction does not significantly modify localization of the nanoconfined active phase.

Previously, the effect of nanoconfinement in FT synthesis has been mostly considered for monometallic iron catalysts. In reality, iron catalysts for FT synthesis contain [1] several components. Iron catalysts are most frequently promoted with copper [17-22]. Copper has very low solubility in metallic iron $(2.7$ at. \% of $\mathrm{Cu}$ in $\mathrm{Fe}$ at $1123 \mathrm{~K})$ [23] and is usually present as a separate metallic phase. Recently, we observed remarkable mobility [24,25] of metal promoters with low melting points such as $\mathrm{Bi}, \mathrm{Pd}, \mathrm{Sb}$ and $\mathrm{Sn}$ in iron catalysts during their activation and FT catalytic reaction. This mobility resulted in the formation of core shell structures identified by a combination of techniques and a major increase in FT reaction rate and light olefin selectivity.

The goal of this work is to evaluate the effect of catalyst preparation, activation and catalytic reaction on the localization, confinement and mobility of iron and copper nanoparticles inside and outside of CNT in bimetallic and monometallic catalysts. The characterization results, which were obtained using a combination of techniques: X-ray diffraction (XRD), conventional X-ray photoelectron spectroscopy (XPS), Near-ambient 
pressure X-ray photoelectron spectroscopy (NAP-XPS), Raman, Scanning Transmission Electron Microscopy (STEM) are discussed together with the catalytic data measured in a higher-pressure fixed-bed reactor.

\section{Experimental}

\section{Catalyst preparation}

Multi-walled CNTs (Iolitec nanomaterial, $95 \%$, length: 5-15 $\mu \mathrm{m}$, outer diameter 20-40 nm) used in this work were pretreated with $34 \mathrm{wt} . \% \mathrm{HNO}_{3}$ at $383 \mathrm{~K}$ under reflux in order to remove the remaining metals and other impurities. This pretreatment also creates defect sites on the surface of CNTs, these surface defects can be considered as anchoring sites for metals. In addition, the hydrophobic nature of CNTs is reduced. The polar functional groups on the surfaces of CNTs during acid treatment, make the surface more accessible to aqueous solutions [26]. In another pretreatment, opening of CNT was enabled [10,27] by treating CNT ( $3.0 \mathrm{~g}$ ) in concentrated $\mathrm{HNO}_{3}(68 \%, 210 \mathrm{~mL})$ for $14 \mathrm{~h}$ at $413 \mathrm{~K}$ under reflux. The treated CNTs samples were then filtered, washed with distilled water and dried overnight in the oven.

The CNTs-supported metals catalysts were fabricated by impregnation with a single metal $(\mathrm{Fe}$ or $\mathrm{Cu})$, co-impregnation with two metals $(\mathrm{Fe}$ and $\mathrm{Cu}$ together) and sequential impregnation (first, copper and then, iron or first, iron and then, copper). The impregnation with a single metal was performed using either open or closed CNTs. For deposition of metal species inside the CNT channels, the open CNTs with the aqueous solution of the metal nitrate were placed for $1 \mathrm{~h}$ in a ultrasonicator. The ultrasonication step helps the metal nitrate solution inducement into the CNT channels $[16,28,29]$ and is also important in terms of better 
dispersion of the particles [30]. Commonly, the dispersion occurs by the formation and collapse of cavitation bubbles, due to extremely high strain rate, which pulls apart the CNTs, originally present in aggregates or bundles.

On the outer surface of the closed CNT, the metal salt was deposited directly by impregnation with the metal nitrate without any pretreatment with ultrasound. For the coimpregnation method, powdery open CNTs $(1.0 \mathrm{~g})$ were first added into a mixed aqueous solution $(40 \mathrm{~mL})$ simultaneously containing copper $(1.75 \mathrm{mmol})$ and iron $(1.99 \mathrm{mmol})$ nitrates, followed by stirring for $3 \mathrm{~h}$ at room temperature. The CNT support and impregnating solution were placed for $1 \mathrm{~h}$ in an ultrasonicator. The mixture was left for $2 \mathrm{~h}$ and then placed in a water bath at $80{ }^{\circ} \mathrm{C}$ with stirring until the solution evaporates. The slurry was then dried at $80{ }^{\circ} \mathrm{C}$ overnight in an oven and then calcined at $400{ }^{\circ} \mathrm{C}$ in the nitrogen flow for $4 \mathrm{~h}$.

The sequential impregnation was used to depose the first metal $(\mathrm{Fe}$ or $\mathrm{Cu})$ inside the CNT channels, while the second metal on the CNT outer surface. CNTs were added to the solution of the first metal. The solution was then placed in the ultrasonicator, agitated in a water bath and subsequently dried in an oven. The catalyst was then calcined in nitrogen flow at $400{ }^{\circ} \mathrm{C}$ for $4 \mathrm{~h}$. The same catalyst sample was used for the impregnation with the second metal in the same sequence (agitation, rest, overflow in a water bath, drying, calcination in nitrogen).

In order to evaluate the influence of exposure to the second step of impregnation on the stability of CNT, Fe-in sample was additionally impregnated with pure deionized water ( $\mathrm{pH} \sim 3$, same $\mathrm{pH}$ as metal nitrate solution used for impregnation). The sample was then dried and calcined using the same procedure as for bimetallic catalyst prepared using two-step 
impregnation. The relevant sample is labeled Fe-in $2^{\text {nd }}$. The targeted $\mathrm{Cu}$ and Fe theoretical contents were $10 \mathrm{wt} . \%$ for each metal in all the catalysts.

\section{Catalyst characterization}

The nitrogen physisorption measurements were carried out using a Micromeritics Tristar 3020 Surface Area and Porosimetry analyzer. Prior to the $\mathrm{N}_{2}$ adsorption, the sample was degassed at $250{ }^{\circ} \mathrm{C}$ for $2 \mathrm{~h}$. The $\mathrm{N}_{2}$ adsorption-desorption isotherms were measured at $-196{ }^{\circ} \mathrm{C}$. The specific surface area of the sample was calculated by the BET method from the isotherms between $\mathrm{P} / \mathrm{P}_{0}=0.05$ and 0.3 , and the average pore volume was estimated using the Barrett-Joyner-Halenda (BJH) method.

A Bruker AXS D8 diffractometer with $\mathrm{Cu} \mathrm{K} \alpha$ radiation $(\lambda=0.153 \mathrm{~nm})$ was used for the X-ray powder diffraction (XRD) measurements. The XRD patterns were collected in the $5-90^{\circ}(2 \theta)$ range, with the $0.02^{\circ}$ step size and $0.5 \mathrm{~s}$ step time. The identification was carried out by comparison with the database from the EVA software. The average crystallite size of the metal nanoparticles was calculated using the diffraction peaks according to the Scherrer equation.

The X-ray fluorescence (XRF) spectroscopy was used to measure the elemental catalyst compositions. The XRF measurements were performed with an energy dispersive micro-X-Ray Fluorescence spectrometer M4 TORNADO (Bruker), equipped with 2 anodes a Rhodium X-ray tube $50 \mathrm{kV} / 600 \mathrm{~mA}(30 \mathrm{~W})$ and a Tungsten X-Ray tube $50 \mathrm{kV} / 700 \mathrm{~mA}(35 \mathrm{~W})$. A Silicon-Drift-Detector $\mathrm{Si}(\mathrm{Li})$ with $<145 \mathrm{eV}$ resolution at 100000 cps $(\mathrm{Mn} \mathrm{K} \alpha)$ was used as a detector and cooled with a Peltier cooling $\left(253^{\circ} \mathrm{K}\right)$. The 
measurements were done under vacuum (20 mbar) and for each sample 36 points (of $200 \mu \mathrm{m}$ ) were analyzed.

The $\mathrm{H}_{2}$ temperature-programmed reduction $\left(\mathrm{H}_{2}-\mathrm{TPR}\right)$ was carried out using the AutoChem II 2920 apparatus (Micromeritics) using $100 \mathrm{mg}$ of the sample in a flow of $\mathrm{H}_{2} / \mathrm{Ar}$ (5 vol. $\% \mathrm{H}_{2}$ ) stream $\left(50 \mathrm{~mL} \mathrm{~min}^{-1}\right)$. The temperature was increased from 50 to $900{ }^{\circ} \mathrm{C}$ at the rate of $10{ }^{\circ} \mathrm{C} \mathrm{min}^{-1}$.

The X-ray photoelectron spectroscopy (XPS) was carried out with a Kratos Axis Ultra

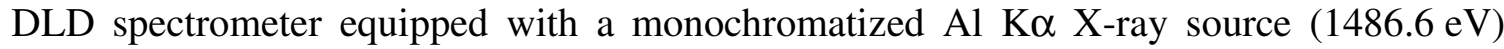
operating at $180 \mathrm{~W} . \mathrm{Fe} 2 \mathrm{p}, \mathrm{Cu} 2 \mathrm{p}, \mathrm{C} 1 \mathrm{~s}$ and $\mathrm{O} 1$ s core level spectra were recorded using a 40 eV Pass Energy. The Binding Energies (BEs) were corrected with respect to C1s fixed at $284.6 \mathrm{eV}$ for the CNT contribution. Relative surface atomic quantification was calculated after the removal of a Shirley type background on each spectrum.

Near ambient pressure X-ray photoelectron spectroscopic measurements (NAP-XPS) were performed in Prague using a spectrometer custom-built by SPECS Surface Nano Analysis, GmbH Germany. An ultrahigh vacuum (UHV) system equipped with a PHOIBOS 150 Hemispheric Energy Analyser and an Al $K \alpha$ monochromatized X-ray source of high intensity (excitation energy of $1486.6 \mathrm{eV}$ ) was employed to perform X-ray photoelectron spectroscopy (XPS) measurements [31]. The in-situ reaction cell was set in the analysis chamber allowing XPS measurements in the presence of gases with pressure up to 10 mbar and at high temperature. Typically, the catalyst $(\sim 20 \mathrm{mg})$ was pressed into a tungsten mesh and together with a K-type thermocouple spot welded to a stainless-steel sample holder. The measurements were performed in presence of carbon monoxide or syngas $(1 \mathrm{mbar})$ at 
temperature ranging from ambient to $350^{\circ} \mathrm{C}$. The XPS spectra were analyzed by fitting the Shirley-type function with the Casa XPS software.

The transmission electron microscopy (TEM) and energy-dispersive X-ray spectroscopy (EDS) characterizations were done using a Thermo Fisher Talos F200X, a FEI Tecnai G2 and a Thermofisher Titan Themis microscopes, operated at 200 and $300 \mathrm{kV}$, respectively. The sample was dispersed in ethanol and a droplet of solution was deposited onto a 400-mesh carbon-coated nickel (or copper) grid. The counting and measurement of the particle size and inner and outer diameters of CNTs follow the same procedure for all samples. A line tool of software Gatan Digital Micrograph was used in order to obtain the values of metal particle size and CNTs diameters. The raw TEM data are available in the Cloud https://nextcloud.univ-lille.fr/index.php/s/oDKeGkKTaEDrzrc. In the case of bimetallic catalysts, we measured three kinds of particles: iron-only, copper-only and interacting iron-copper particles. For each sample, we plotted a histogram of the measurements, the distribution of the particles size and CNTs diameters. The particle sizes were calculated using the Sauter mean diameter equation [32].

The Raman spectroscopy was performed in Horiba XploRA plus spectrometer, equipped with CCD syncerity detector cooled by the Peltier effect, 2 laser sources: $532 \mathrm{~nm}$, 785 nm, 4 networks: 600,1200,1600 and 2400 lines / mm, xyz motorized stage and fiber optical. The Raman spectra were carried out at the excitation wavelength of $785 \mathrm{~nm}$, the objective 100 , the filter at $1 \%$, the source 1200 and the step of $120 \mathrm{~s}^{-1}$, in the spectral range from 100 to $1800 \mathrm{~cm}^{-1}$. The Raman spectra have been registered in two spectral regions: D (disorder-induced) and G (graphene) bands. 


\section{Catalytic reaction}

The catalytic conversion of syngas was performed in a fixed-bed reactor with an inner diameter of $8.0 \mathrm{~mm} .0 .2 \mathrm{~g}$ of fresh catalyst was loaded into the reactor. Prior to the reaction, the catalyst was activated under the $\mathrm{CO}$ gas flow $\left(50 \mathrm{~mL} \mathrm{~min}^{-1}\right)$ at atmospheric pressure and $623 \mathrm{~K}$ for $10 \mathrm{~h}$ (at a rate of $\left.2{ }^{\circ} \mathrm{C} \mathrm{min}-1\right)$. For the $\mathrm{Cu}$-in and $\mathrm{Cu}$-out catalysts, the activation was under $\mathrm{H}_{2}$ gas flow $\left(50 \mathrm{~mL} \mathrm{~min}^{-1}\right.$ ) at atmospheric pressure and $573 \mathrm{~K}$ for $5 \mathrm{~h}$ (at a rate of $\left.2{ }^{\circ} \mathrm{C} \min ^{-1}\right)$.

Table 1. Physical properties of supports and supported $\mathrm{Cu}$ and $\mathrm{Fe}$ catalysts

\begin{tabular}{|c|c|c|c|c|c|c|c|c|}
\hline Sample & $\begin{array}{l}\mathrm{S}_{\mathrm{BET}^{\mathrm{a}}} \\
\left(\mathrm{m}^{2} / \mathrm{g}\right)\end{array}$ & $\begin{array}{l}\mathrm{V}_{\text {tot }}^{\mathrm{b}} \\
\left(\mathrm{cm}^{3} / \mathrm{g}\right)\end{array}$ & $\begin{array}{l}\mathrm{D}_{\text {meso }}{ }^{\mathrm{c}} \\
(\mathrm{nm})\end{array}$ & \multicolumn{2}{|l|}{$\begin{array}{l}D_{\text {crystallite }}{ }^{d} \\
(\mathrm{~nm})\end{array}$} & $\begin{array}{l}\text { Total } \mathrm{H}_{2} \\
\text { consumption }^{\mathrm{e}} \\
(\mathrm{mmol} / \mathrm{g})\end{array}$ & \multicolumn{2}{|c|}{$\begin{array}{l}\mathrm{Cu} \text { or } \mathrm{Fe} \text { content } \\
(\mathrm{wt} \%)\end{array}$} \\
\hline $\begin{array}{l}\text { CNTs } \\
\text { commercial }\end{array}$ & 76.9 & 0.19 & 14.1 & \multicolumn{2}{|l|}{ - } & - & \multicolumn{2}{|l|}{-} \\
\hline CNTs out & 88.3 & 0.21 & 13.5 & \multicolumn{2}{|l|}{-} & - & \multicolumn{2}{|l|}{-} \\
\hline CNTs in & 157.1 & 0.38 & 11.4 & \multicolumn{2}{|l|}{-} & - & \multicolumn{2}{|l|}{-} \\
\hline Fe-in & 154.4 & 0.35 & 10.7 & \multicolumn{2}{|l|}{$\mathrm{Fe}_{2} \mathrm{O}_{3}: 27$} & 2.3 & \multicolumn{2}{|l|}{ Fe: 8.2} \\
\hline $\mathrm{Fe}$-out & 104.5 & 0.26 & 11.6 & \multicolumn{2}{|l|}{$\mathrm{Fe}_{2} \mathrm{O}_{3}: 30$} & 2.1 & \multicolumn{2}{|l|}{ Fe: 4.5} \\
\hline $\mathrm{Cu}$-in & 136.1 & 0.38 & 11.1 & \multicolumn{2}{|l|}{ CuO: 14} & 1.9 & \multicolumn{2}{|l|}{ Cu: 2.8} \\
\hline $\mathrm{Cu}$-out & 106.2 & 0.23 & 11.6 & \multicolumn{2}{|l|}{$\mathrm{CuO}: 26$} & 1.8 & \multicolumn{2}{|l|}{ Cu: 1.3} \\
\hline $\mathrm{Fe}^{1 \mathrm{st}} \mathrm{Cu}^{2 \mathrm{nd}}$ & 130.2 & 0.28 & 11.2 & $\mathrm{Fe}_{2} \mathrm{O}_{3}: 25$ & $\mathrm{CuO}: 23$ & 5.2 & Fe: 6.5 & $\mathrm{Cu}: 6.6$ \\
\hline $\mathrm{Cu}^{1 \mathrm{st}} \mathrm{Fe}^{2 \mathrm{nd}}$ & 152.4 & 0.34 & 10.7 & $\mathrm{Fe}_{2} \mathrm{O}_{3}: 18$ & $\mathrm{CuO}: 23$ & 4.8 & Fe: 6.9 & $\mathrm{Cu}: 5.2$ \\
\hline $\mathrm{Fe}+\mathrm{Cu}$-in & 133.9 & 0.35 & 11.3 & \multicolumn{2}{|c|}{$\mathrm{CuFe}_{2} \mathrm{O}_{2} / \mathrm{CuO}: 10$} & 3.9 & Fe: 5.4 & $\mathrm{Cu}: 5.2$ \\
\hline $\mathrm{Fe}+\mathrm{Cu}$-out & 91.1 & 0.23 & 10.6 & \multicolumn{2}{|c|}{$\mathrm{CuFe}_{2} \mathrm{O}_{2} / \mathrm{CuO}: 21$} & 3.8 & Fe: 3.7 & $\mathrm{Cu}: 3.3$ \\
\hline
\end{tabular}

${ }^{\text {aBET Surface Area }}$

bJH Desorption cumulative volume of pores between $17.000 \AA$ and 3,000.000 $\AA$

${ }^{\mathrm{c}} \mathrm{BJH}$ Desorption average pore width (4V/A)

${ }^{\mathrm{d}}$ Size of crystallites by XRD (Scherrer equation)

${ }^{\mathrm{e}}$ The total $\mathrm{H}_{2}$ consumption from TPR analysis

${ }^{\mathrm{f}} \mathrm{The} \mathrm{Fe}$ and $\mathrm{Cu}$ content from XRF analysis 
The reactor was cooled down to $453 \mathrm{~K}$ and a syngas flow with a $\mathrm{H}_{2} / \mathrm{CO}$ ratio of $1 / 1$ was introduced into the reactor. Nitrogen with a flow of $1 \mathrm{~mL} \min ^{-1}$ in the syngas was used as an internal standard for the calculation of $\mathrm{CO}$ conversion. The pressure of syngas was typically regulated to 10 bar. After collecting bypass, the temperature started to increase with a heating rate of $1 \mathrm{~K} \mathrm{~min}^{-1}$ until the temperature of $623 \mathrm{~K}$ to start the reaction.

The reaction products were analyzed online by a gas chromatograph (Bruker GC450). $\mathrm{N}_{2}, \mathrm{CO}, \mathrm{CO}_{2}$, and $\mathrm{CH}_{4}$ were separated by a packed CTR-1 column and were analyzed by a thermal conductivity detector (TCD). The produced $\mathrm{C}_{1}$ to $\mathrm{C}_{9}$ hydrocarbons and alcohols were separated by a Rt-Q-PLOT capillary column and analyzed by a flame ionization detector (FID). The catalytic performance at $20 \mathrm{~h}$ of reaction was used for catalyst comparison. Further details of catalytic experiments are available from Supplementary Material (SM).

\section{Results and Discussion}

\section{Characterization of calcined catalysts}

The XRF, XRD, TPR, and nitrogen adsorption data for the monometallic and bimetallic catalysts are presented in Table 1. The catalysts with non-confined and confined iron and/or copper nanoparticles do not present similar iron and copper contents measured by XRF. At the same time, the targeted value should be around $10 \mathrm{wt} \%$ for all of them. In the confined catalysts, the metal content is higher than in non-confined counterparts. Note that the metals were deposited over the catalysts using impregnation followed by evaporation of the impregnating solution. Some amount of the deposited metal species can be removed 
during the washing step. Table 1 also shows textural properties of the CNTs supports without acid treatment (commercial form) and CNT with open and closed channels, for confined particles (in) and non-confined particles (out), and also for the catalysts containing iron and copper nanoparticles located either outside (non-confined) or inside the CNTs tubes (confined).

The surface area of CNTs increases after the acid treatments. As expected, the severe acid treatment used to open the channels, produces a higher impact on the surface area and pore volume, while the mild acid treatment has a much lower impact. CNTs with open tubes (CNTs-in) exhibit a larger pore volume compared with CNTs with closed tubes (CNTs-out). After the impregnation with iron and copper, the surface area decreases for the catalysts with the metal particles presumably located inside of the tubes and increases for the catalysts with the metal particles outside CNT. The addition of iron and copper to CNT leading to the Fein and $\mathrm{Cu}$-in samples results in a decrease in the surface area of CNTs from 157.1 to 154.4 and $136.1 \mathrm{~m}^{2} \mathrm{~g}^{-1}$, respectively. He et al. [33] also observed that both surface area and pore volume values decreased after a severe acid treatment followed by the impregnation with iron and copper. Similar effect was also observed by Chen et al.[34] who used CNTs as a support for preparation of platinum nanocatalysts. Gu et al.[10] observed that the impregnation with iron produced only a very small impact on the pore volume of CNT with closed tubes. However, when the metal particles are located inside the CNTs tubes, a very significant decrease was observed. 
a) Fe-out and Fe-in

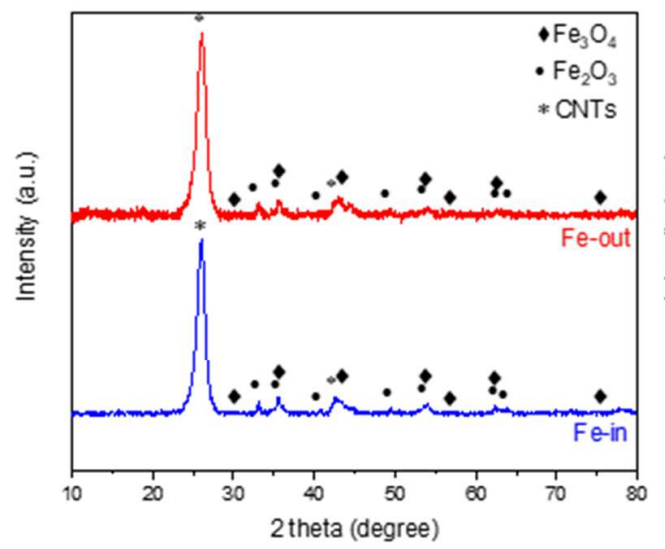

c) $\mathrm{Fe}+\mathrm{Cu}$-out and $\mathrm{Fe}+\mathrm{Cu}$-in

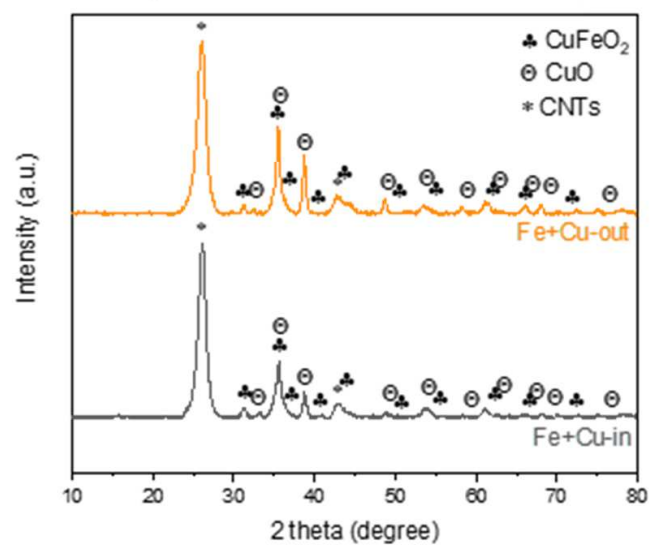

b) $\mathrm{Cu}$-out and $\mathrm{Cu}$-in

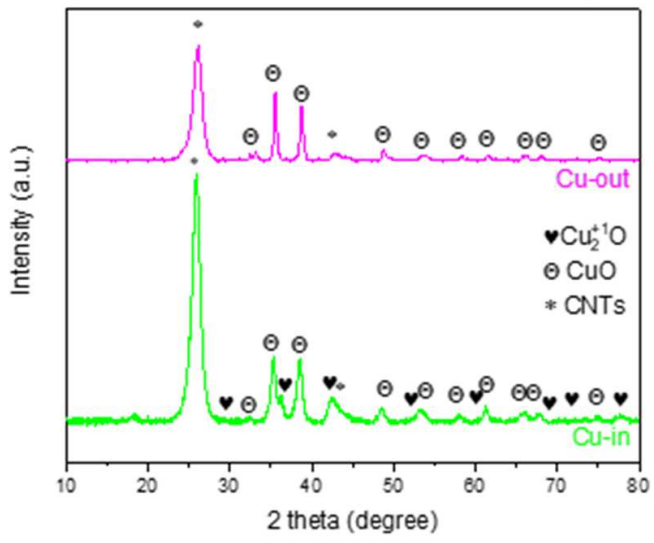

d) $\mathrm{Cu}^{1 \text { st }} \mathrm{Fe}^{2 \text { nd }}$ and $\mathrm{Fe}^{\text {sts }} \mathrm{Cu}^{2 \text { nd }}$

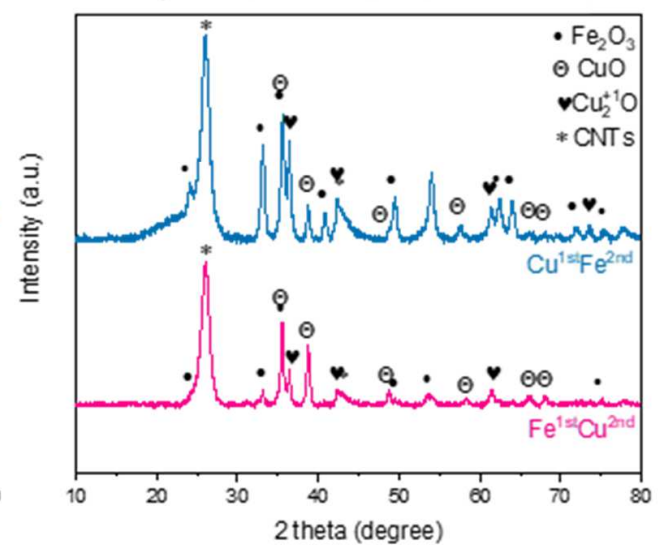

Figure 1. XRD patterns of calcined catalysts

For the $\mathrm{Fe}^{1 s t} \mathrm{Cu}^{2 \text { nd }}, \mathrm{Cu}^{1 \text { st }} \mathrm{Fe}^{2 \text { nd }}, \mathrm{Fe}+\mathrm{Cu}$-in and $\mathrm{Fe}+\mathrm{Cu}$-out bimetallic catalysts, the surface area decreases to $130.2,152.4,133.9$ and $91.1 \mathrm{~m}^{2} \mathrm{~g}^{-1}$, respectively. The decrease in the surface area and pore volume of open CNT after impregnation with the iron or copper precursors can be due to two phenomena. First, the introduction of metals may result in the effect of "dilution" of CNTs, reducing the weight normalized surface area. Second, the impregnation can lead to blocking of CNT inner channels with metal species [35]. Note however, that some increase in the BET surface area from 88.3 to 104.5 and $106.2 \mathrm{~m}^{2} \mathrm{~g}^{-1}$ was 
observed for the $\mathrm{Fe}$-out and $\mathrm{Cu}$-out catalysts compared to their corresponding support (CNTs-out). CNT with closed channels does not have a highly developed mesoporosity. Introduction of metals can generate some defects on the surface of closed CNT and favor CNT redispersion. This could result in some surface area increase.

Figure $1 \mathbf{a}, \mathbf{b}, \mathbf{c}$ and $\mathbf{d}$ displays XRD profiles of the calcined supported catalysts. The detailed assignment of XRD peaks in the calcined catalysts is given in Table S1, SM. For all monometallic and bimetallic calcined catalysts, the XRD patterns show diffraction peaks at $26.4^{\circ}$ and $42.9^{\circ}$ attributed to the $\left(\begin{array}{lll}0 & 0 & 2\end{array}\right)$ and $\left(\begin{array}{lll}1 & 0 & 0\end{array}\right)$ reflections of the CNTs supports [3,5,33,36-38] (\#PDF 01-0646). This indicates that the crystal structure of CNTs is maintained after the acid treatments and metal impregnation [3]. Interestingly, the relative intensity peak of copper oxide relative to the CNT peak is higher for non-confined copper monometallic catalyst in comparison with the confined one. This could be due to different copper oxide particle size, which in the case of non-confined copper monometallic catalyst is 1.8 times larger than in the confined counterpart

The peaks in the XRD patterns of the Fe-in, Fe-out, $\mathrm{Fe}^{1 \mathrm{st}} \mathrm{Cu}^{2 \text { nd }}$ and $\mathrm{Cu}^{1 \text { st }} \mathrm{Fe}^{2 \text { nd }}$ samples at $33.1,35.6,40.8,49.5,54,62.4$ and $64.1^{\circ}$ are assignable to the hematite phase $\left(\mathrm{Fe}_{2} \mathrm{O}_{3}\right)[3,5,36,37]$ (\#PDF 01-1053), while the peaks at 30, 35.5, 43, 53.5, 57, 62.5 and 74.1 ${ }^{\circ}$ can be attributed to the magnetite phase $\left(\mathrm{Fe}_{3} \mathrm{O}_{4}\right)[3,5,33,37,38]$ (\#PDF 01-1111). In the iron containing catalysts, calcined at $400{ }^{\circ} \mathrm{C}$ in the nitrogen atmosphere, the iron species exist as a mixture of $\mathrm{Fe}_{2} \mathrm{O}_{3}$ and $\mathrm{Fe}_{3} \mathrm{O}_{4}[5]$.

The calcined copper-containing catalysts exhibit peaks attributed to the $\mathrm{CuO}$ tenorite and $\mathrm{Cu}_{2} \mathrm{O}$ cuprite phases. For the $\mathrm{Cu}$-in, $\mathrm{Cu}$-out monometallic catalysts and $\mathrm{Fe}^{1 \mathrm{st}} \mathrm{Cu}^{2 \text { nd }}, \mathrm{Cu}^{1 \mathrm{st}}$ $\mathrm{Fe}^{2 \mathrm{nd}}, \mathrm{Fe}+\mathrm{Cu}$-in and $\mathrm{Fe}+\mathrm{Cu}$-out bimetallic samples, the peaks at 32.5, 35.4, 38.6, 48.8, 53.4, 
$58.3,61.6,66.2,68.1$ and $75.1^{\circ}$ can be attributed to the (llll 110$),\left(\begin{array}{lll}0 & 0 & 2\end{array}\right),\left(\begin{array}{lll}1 & 1 & 1\end{array}\right),\left(\begin{array}{lll}-2 & 0 & 2\end{array}\right)$, ( $\left.\begin{array}{lll}0 & 2 & 0\end{array}\right),\left(\begin{array}{lll}2 & 0 & 2\end{array}\right),\left(\begin{array}{lll}-1 & 1 & 3\end{array}\right),\left(\begin{array}{lll}-3 & 1 & 1\end{array}\right),\left(\begin{array}{lll}2 & 2 & 0\end{array}\right)$ and $\left(\begin{array}{llll}0 & 0 & 4\end{array}\right)$ reflections of tenorite phase (CuO)[33,39-42](\#PDF 05-0661), respectively (Table S1, SM). For the Cu-in catalyst, the peaks at $29.5,36.3,42.4,52.5,61.3,69.5,73.5$ and $77.2^{\circ}$ could be assigned to the $\left(\begin{array}{lll}1 & 1 & 0\end{array}\right)$,

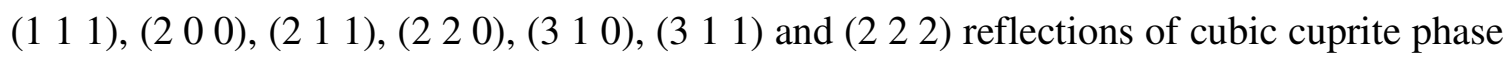
$\left(\mathrm{Cu}_{2} \mathrm{O}\right)[40,41,43,44](\# \mathrm{PDF}$ 05-0667). For the bimetallic catalyst $\mathrm{Fe}+\mathrm{Cu}$-in and $\mathrm{Fe}+\mathrm{Cu}-\mathrm{out}$, the peaks at $31.3,34.5,35.6,40.2,43.4,47.7,55.2,61,64.8$ and $70^{\circ}$ can be attributed to the (l $\left.\begin{array}{lll}0 & 6\end{array}\right),\left(\begin{array}{lll}1 & 0 & 1\end{array}\right),\left(\begin{array}{lll}0 & 1 & 2\end{array}\right),\left(\begin{array}{lll}1 & 0 & 4\end{array}\right),\left(\begin{array}{lll}0 & 1 & 5\end{array}\right),\left(\begin{array}{lll}0 & 0 & 9\end{array}\right),\left(\begin{array}{lll}0 & 1 & 8\end{array}\right),\left(\begin{array}{lll}1 & 1 & 0\end{array}\right),\left(\begin{array}{lll}1 & 0 & 10\end{array}\right)$ and $\left(\begin{array}{lll}0 & 1 & 1\end{array}\right)$ reflections of delafossite phase $\left(\mathrm{CuFeO}_{2}\right)$ (\#PDF 03-0870).

The crystallite sizes of iron and copper oxides were calculated from the XRD peak broadening using the Scherrer equation (Table S2, SM). The crystallite sizes measured by $\mathrm{XRD}$ were in the range from 20 to $30 \mathrm{~nm}$ for both copper and iron species, with the exception for $\mathrm{Cu}$-in. In this sample, XRD detected smaller copper oxide crystallites of 5-14 nm. Note that measuring sizes of crystallites from the half-width of the diffraction profile could slightly overestimate [45] the crystallite diameters. In addition, some very small metal oxide particles could be missed by XRD, because of significant XRD line broadening, while others can adopt an elongated shape in the pores.

In order to provide further information about the sizes and localization of metal oxide nanoparticles, the catalysts and CNT supports were characterized by TEM. First, we measured inner and outer diameter distributions for the CNT supports (Figure S1, SM). The size distribution is broad, with the internal average diameter of 8.4-9.9 $\mathrm{nm}$, and the outer average diameter of 42.7-43.9 $\mathrm{nm}$ for both CNTs-in and CNTs-out (See Table S3, SM). 

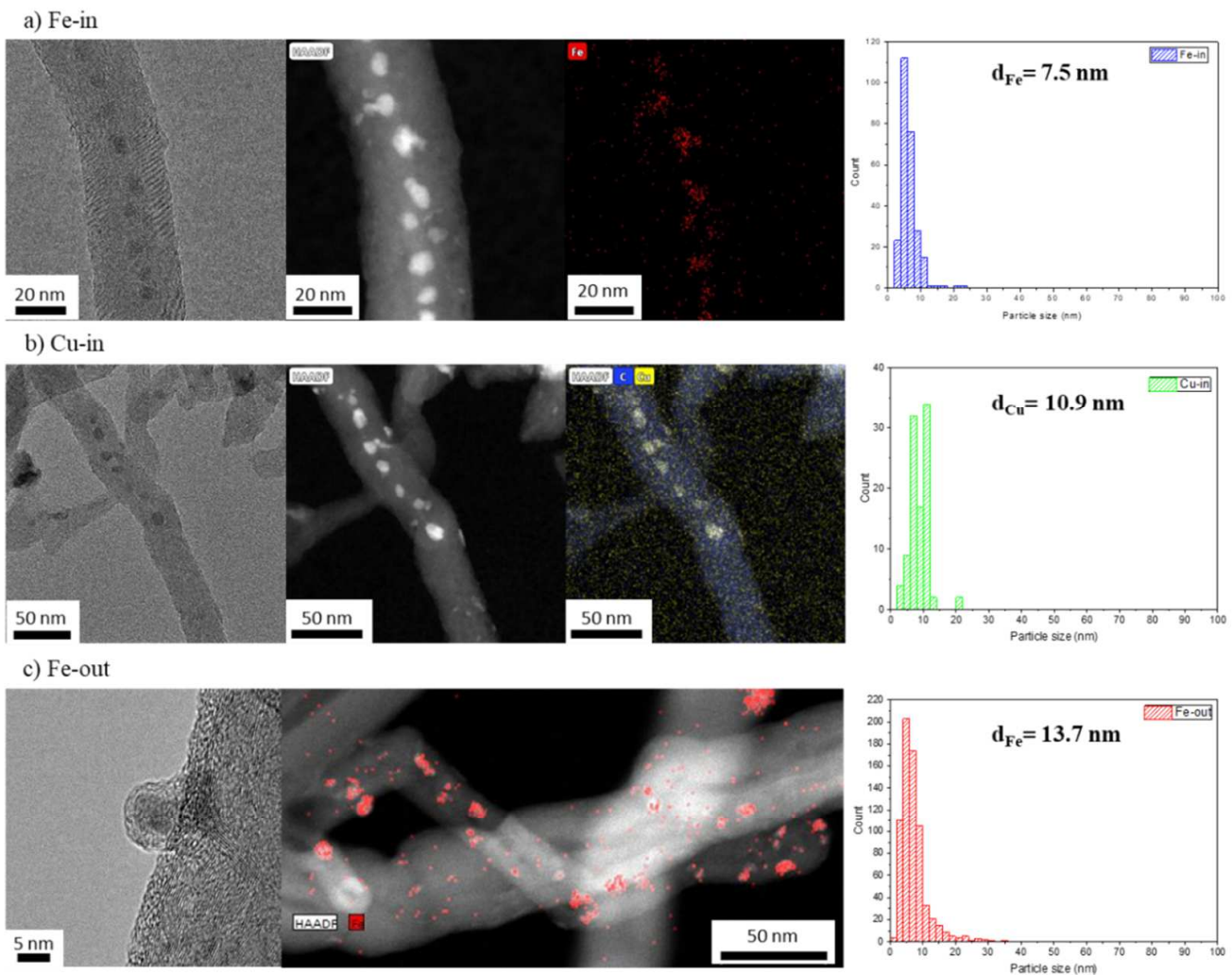

d) $\mathrm{Fe}^{1 \mathrm{st}} \mathrm{Cu}^{2 \mathrm{nd}}$
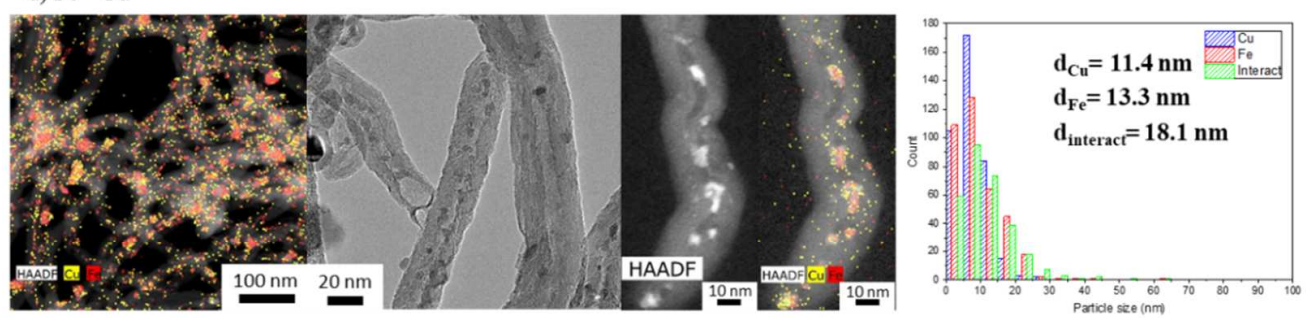

e) $\mathrm{Cu}^{1 \mathrm{st}} \mathrm{Fe}^{2 \mathrm{nd}}$
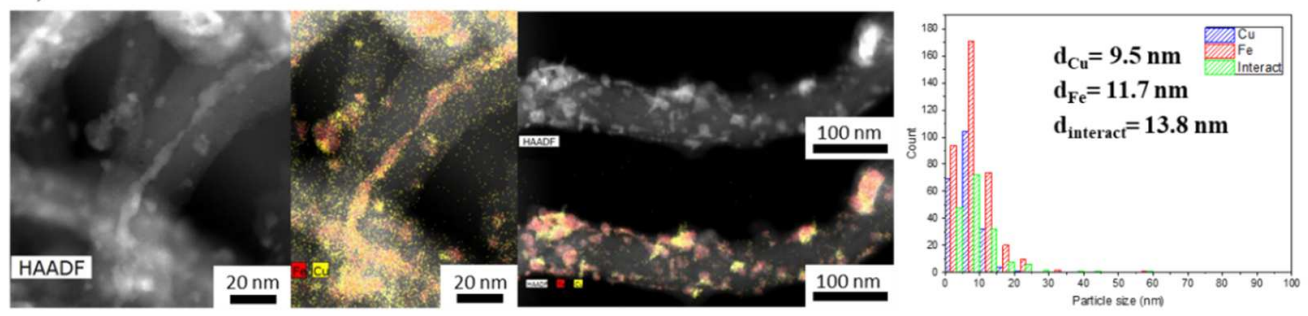

Figure 2. TEM micrographs and histograms of particle size distribution for the freshly calcined supported catalysts. 
. Figure 2 displays TEM micrographs of the freshly calcined CNT-supported catalysts. Several hundreds of nanoparticles were taken for calculating nanoparticle size histograms and evaluation of the localization of iron and copper nanoparticles inside and outside CNT. Note that HAADF-STEM and Z-contrast alone do not allow the identification of chemical composition of copper and iron nanoparticles. That was the reason, why for the bimetallic catalysts, EDS was applied for identification of the chemical particle composition. We considered the largest diameter of nanoparticles in the particle size measurements.

Table 2. The average particle size of the catalysts before and after the reaction

\begin{tabular}{|l|l|l|l|}
\hline \multicolumn{2}{|l|}{ Before reaction } & After reaction & \\
\hline Sample & Sauter D $(\mathrm{nm})$ & Sample & Sauter D $(\mathrm{nm})$ \\
\hline Fe-in & 7.5 & Fe-in used & 15.1 \\
\hline Fe-out & 13.7 & Fe-out used & 18.8 \\
\hline $\mathrm{Cu}$-in & 10.9 & $\mathrm{Cu}$-in used & 14.0 \\
\hline \multirow{2}{*}{$\mathrm{Fe}^{1 \text { st }} \mathrm{Cu}^{\text {2nd }}$} & $\begin{array}{l}\text { Cu: } 11.4 \\
\text { Fe: } 13.3 \\
\text { Interacting: } 18.1\end{array}$ & $\mathrm{Fe}^{1 \text { st }} \mathrm{Cu}^{2 \text { nd }}$ used & $\begin{array}{l}\text { Cu: } 27.2 \\
\text { Fe: } 18.3 \\
\text { Interacting: } 34.7\end{array}$ \\
\hline \multirow{2}{*}{$\mathrm{Cu}^{1 \text { st }} \mathrm{Fe}^{2 \text { nd }}$} & $\begin{array}{l}\text { Cu: } 9.5 \\
\text { Fe: } 11.7 \\
\text { Interacting: } 13.8\end{array}$ & $\mathrm{Cu}^{1 \text { st }} \mathrm{Fe}^{\text {2nd }}$ used & $\begin{array}{l}\text { Cu: } 18.3 \\
\text { Fe: } 20.7 \\
\text { Interacting: } 23.3\end{array}$ \\
\hline
\end{tabular}

Moreover, TEM images also allowed identification of the nanoparticle localization either inside or outside of CNTs. For each analyzed catalyst, we built histograms of copper, iron individual, and interacting metal nanoparticle distribution localized inside and outside of CNT. The average particle size for $\mathrm{Cu}, \mathrm{Fe}$, and interacting particles were calculated from the histograms using the Sauter equation. The average (Sauter) particle sizes calculated from TEM images are presented in Table 2 . We detected three types of metal oxide nanoparticles in the CNT supported catalysts: isolated copper oxide nanoparticles, isolated iron oxide nanoparticles and interacting copper-iron oxide nanoparticles. The particles are considered 
"interacting", if the TEM images clearly show their close intimate contact. The distribution of copper, iron and interacting particles inside and outside of CNT is given in Table 3.

The TEM images for the freshly calcined Fe-in catalyst exhibit iron oxide particles with an average size of $8.8 \mathrm{~nm}$ and a narrow particle size distribution. The fresh $\mathrm{Cu}$-in catalyst also presents an average size of $10.9 \mathrm{~nm}$. TEM images clearly confirm the presence of a larger fraction of iron and copper nanoparticles inside the CNTs tubes (83\% for Fe-in and 78\% for Cu-in, Table 3). The iron and copper localization inside open CNT is due to the tubular morphology of CNTs, which can induce capillary forces to absorb the Fe or $\mathrm{Cu}$ nitrate solutions into the tubes during the impregnation [15]. Due to their confinement inside the tubes, the nanoparticle growth seems to be limited by the inner walls of the CNTs $[10,46,47]$. Our results are consistent with the data of Chen et al. [48] who observed that the size of confined iron oxide nanoparticles changed according to the inner diameter. The larger is the internal diameter of the CNTs, the larger is the confined particle.

Table 3. Particle location inside and outside CNT before and after the reaction.

\begin{tabular}{|c|c|c|c|c|c|c|c|c|}
\hline \multirow{2}{*}{ Catalyst } & \multicolumn{4}{|c|}{ Before reaction } & \multicolumn{4}{|l|}{ After reaction } \\
\hline & \multicolumn{2}{|c|}{$\%$ of particles in } & \multicolumn{2}{|c|}{$\%$ of particles out } & \multicolumn{2}{|c|}{$\%$ of particles in } & \multicolumn{2}{|c|}{$\%$ of particles out } \\
\hline Fe-in & \multicolumn{2}{|l|}{78.0} & \multicolumn{2}{|l|}{22.0} & \multicolumn{2}{|l|}{72.2} & \multicolumn{2}{|l|}{27.8} \\
\hline Fe-out & \multicolumn{2}{|l|}{7.5} & \multicolumn{2}{|l|}{92.5} & \multicolumn{2}{|l|}{12.6} & \multicolumn{2}{|l|}{87.4} \\
\hline \multirow[t]{2}{*}{ Cu-in } & \multicolumn{2}{|l|}{83.0} & \multicolumn{2}{|l|}{17.0} & \multicolumn{2}{|l|}{58.2} & \multicolumn{2}{|l|}{41.8} \\
\hline & $\begin{array}{l}\% \text { of } \\
\text { Interacting } \\
\text { particles }\end{array}$ & $\begin{array}{l}\% \\
\text { in }\end{array}$ & articles & $\begin{array}{l}\% \text { of particles } \\
\text { out }\end{array}$ & \begin{tabular}{|l|}
$\%$ \\
Interacting \\
particles
\end{tabular} & $\begin{array}{l}\% \\
\text { in }\end{array}$ & particles & $\begin{array}{l}\% \text { of particles } \\
\text { out }\end{array}$ \\
\hline $\mathrm{Fe}^{1 \mathrm{st}} \mathrm{Cu}^{2 \mathrm{nd}}$ & 39.8 & $\begin{array}{l}\mathrm{Cu} \\
\mathrm{Fe}: \\
\text { Int: }\end{array}$ & & $\begin{array}{l}\text { Cu: } 66.4 \\
\text { Fe: } 63.2 \\
\text { Int: } 59.2\end{array}$ & 7.8 & & $\begin{array}{l}1.9 \\
5.5 \\
.6\end{array}$ & $\begin{array}{l}\text { Cu: } 88.1 \\
\text { Fe: } 74.5 \\
\text { Int: } 94.4\end{array}$ \\
\hline $\mathrm{Cu}^{1 \mathrm{st}} \mathrm{Fe}^{2 \mathrm{nd}}$ & 29.4 & $\begin{array}{l}\mathrm{Cu} \\
\mathrm{Fe}: \\
\text { Int: }\end{array}$ & & $\begin{array}{l}\text { Cu: } 67.6 \\
\text { Fe: } 79.8 \\
\text { Int: } 63.7\end{array}$ & 23.7 & & $\begin{array}{l}9.1 \\
4.8 \\
0.4\end{array}$ & $\begin{array}{l}\text { Cu: } 50.9 \\
\text { Fe: } 45.2 \\
\text { Int: } 69.6\end{array}$ \\
\hline
\end{tabular}


The metal particles are larger, when the metal species are deposited on the outer surface of closed CNT. For the Fe-out catalyst, the particle size distribution is broad with the average size of $13.7 \mathrm{~nm}$ (Figure 2, Table 2). Note that $92.5 \%$ iron particles in Fe-out are located outside CNT (Table 3).

In the bimetallic $\mathrm{Fe}^{1 \mathrm{st}} \mathrm{Cu}^{2 \text { nd }}$ and $\mathrm{Cu}^{1 s t} \mathrm{Fe}^{2 \text { nd }}$ catalysts, the sizes of iron, copper and interacting nanoparticles are in the range from 9.5 to $14.0 \mathrm{~nm}$. The calcined $\mathrm{Fe}^{1 \mathrm{st}} \mathrm{Cu}^{2 \text { nd }}$ and $\mathrm{Cu}^{1 \mathrm{st}} \mathrm{Fe}^{\text {2nd }}$ catalysts were prepared from $\mathrm{Fe}$-in and $\mathrm{Cu}$-in with subsequent impregnation with respectively, copper or iron nitrate. Interestingly, the second impregnation significantly modifies the distribution of metal oxide nanoparticles introduced during the first impregnation. After the first impregnation, most of iron or copper nanoparticles are located inside the CNT channels. After the second impregnation, it seems that a major fraction of metal nanoparticles migrates from inside CNT to the outer surface. Most of isolated monometallic or interacting nanoparticles are located on the CNT outer surface.

TEM suggests considerable migration of metal nanoparticles in the catalysts prepared by sequential two-step impregnation. The acid treatment of the support and impregnation method can damage CNTs and thus, facilitate the mobility of metal nanoparticles. Note that the ultrasonication can contribute to the defects in CNTs. Both longer sonication time and use of high frequency can result in cutting of carbon nanotubes into shorter lengths [49-52]. Ultrasonicate can also contribute to the migration and redispersion of metals.

To confirm this hypothesis, Raman spectroscopic measurements were performed for all the catalysts. It has been shown [53] that Raman spectroscopy can be particularly sensitive to the microstructure of the carbon. This technique provides therefore, a nondestructive control of structural and electronic characteristics of carbon materials [54]. Figure S2, SM 
shows the Raman spectra of the commercial CNTs (in grey), CNTs after severe acid treatment (CNTs-in) and CNTs after the mild acid treatment (CNTs-out). The bands D $\left(\sim 1350 \mathrm{~cm}^{-1}\right)$ and G- $\left(\sim 1580 \mathrm{~cm}^{-1}\right)$ reveal the presence of defects in the graphite layer [55]. A good indicator of the quality of bulk CNT samples is the ratio of the intensities of D and G bands: if these intensities are similar, it indicates a high quantity of structural defects [56].
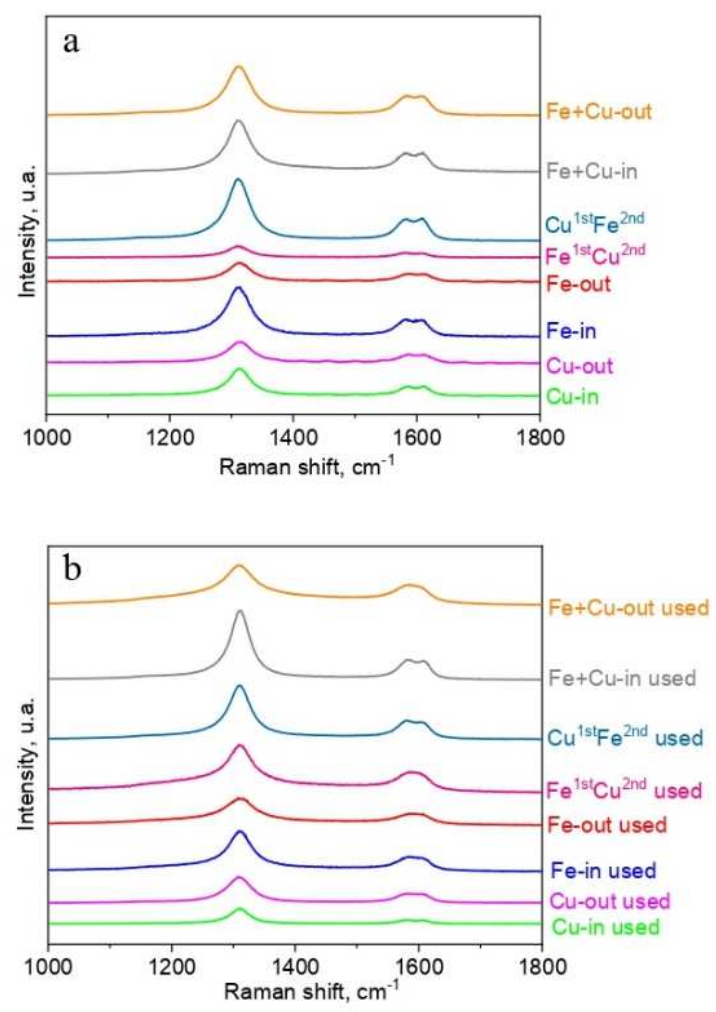

Figure 3. Raman spectra of calcined (a) and used (b) catalysts (excitation wavelength of $785 \mathrm{~nm})$

The Raman spectra of calcined catalysts are presented in Figure 3. The ratios of D and $\mathrm{G}$ bands $\left(\mathrm{I}_{\mathrm{D}} / \mathrm{I}_{\mathrm{G}}\right)$ are shown in Table S4, SM. A smaller intensity ratio of D- and G-bands $\left(\mathbf{I}_{\mathbf{D}} / \mathbf{I}_{\mathbf{G}}\right)$ indicates a higher degree of graphitization and less damage of CNTs[55]. Table S4, SM shows that sequential two-step impregnation provokes more damages in the CNTs 
structures than the co-impregnation $(\mathrm{Fe}+\mathrm{Cu}$-in and $\mathrm{Fe}+\mathrm{Cu}$-out $)$ and single-step impregnation (Fe-in, $\mathrm{Fe}$-out, $\mathrm{Cu}$-in and $\mathrm{Cu}$-out).

In addition to the variation of the intensities, a high frequency shift of the $G$ bands is observed. This shift is possibly related to the structural defects or residual strains in CNTs [55]. The high frequency shift, especially for the $G$ band, could be attributed to disentanglement and dispersion of the CNTs bundles. This deformation on CNTs could result in a change in $\mathrm{C}-\mathrm{C}$ bond vibrations, which in turn, leads to a change in the vibrational frequencies of the normal modes and thus to Raman band shifts [57]. The $I_{D} / I_{G}$ ratio increases with the number of impregnation steps. This indicates formation of defect CNT structure, which reduces the efficient length of CNT and creates orifices. The information obtained by Raman spectroscopy is also consistent with the TEM data. Figure S4, SM allows visualization of the defects provoked by the second step of impregnation in used catalysts. In the left images, it is possible to observe longer CNTs and also it is possible to view better the channel limits.

In contrast, in the images on the right, the CNTs are shorter and the channel limits are not that easy to see anymore. These visual observations are consistent with the Raman results, that show higher concentration of defects in the catalysts prepared with two steps of impregnation, comparing with the other catalysts prepared by single-step impregnation. The presence of numerous defects in the $\mathrm{Fe}^{1 \mathrm{st}} \mathrm{Cu}^{\text {nnd }}$ and $\mathrm{Cu}^{1 \text { st }} \mathrm{Fe}^{2 \text { nd }}$ catalysts prepared by successive impregnations could possibly explain facile migration of metal nanoparticles. In order to evaluate the effect of impregnation on the structure of the Fe-in monometallic catalyst, this catalyst was impregnated with deionized water $(\mathrm{pH} \sim 3$ adjusted by nitric acid, same $\mathrm{pH}$ as in metal nitrate solution). The impregnation with acid water also results in the 
modification of the Raman spectra (Figure S3, SM) and in the increase in the $\mathbf{I}_{\mathbf{D}} / \mathbf{I}_{\mathbf{G}}$ intensity ratio to the value observed for the bimetallic $\mathrm{Fe}^{1 \mathrm{st}} \mathrm{Cu}^{2 \text { nd }}$ and $\mathrm{Cu}^{1 \mathrm{st}} \mathrm{Fe}^{2 \text { nd }}$ samples (Table $\mathbf{S 4}$, sample Fe-in $2^{\text {nd }}, \mathbf{S M}$ ). This suggests that each impregnation step (even exposure to pure water) decreases the ordering of CNT.

a) $\mathrm{Fe}$-in and $\mathrm{Fe}$-out

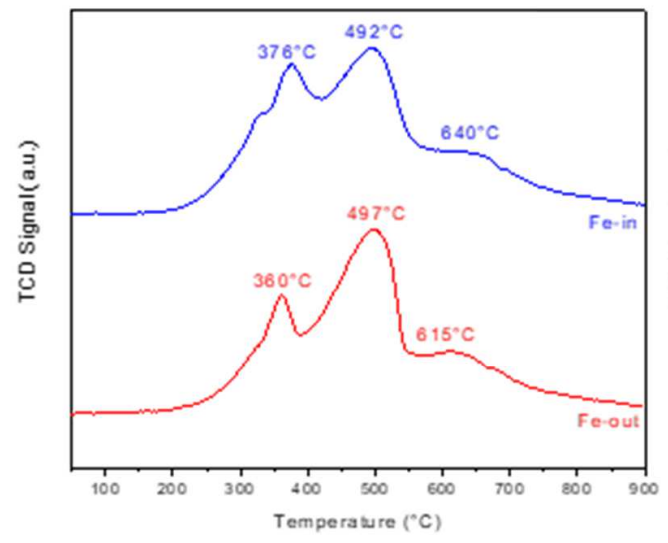

c) $\mathrm{Fe}+\mathrm{Cu}$-in and $\mathrm{Fe}+\mathrm{Cu}-\mathrm{out}$

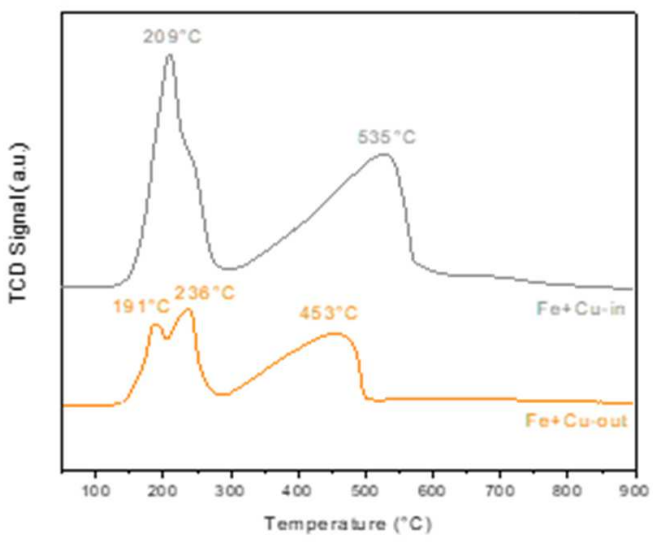

b) $\mathrm{Cu}$-in and $\mathrm{Cu}-\mathrm{out}$

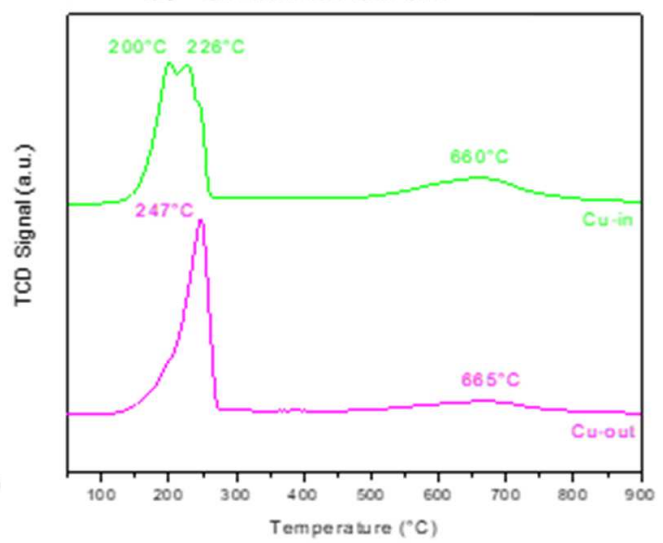

d) $\mathrm{Fe}^{1 \mathrm{st}} \mathrm{Cu}^{2 \mathrm{nd}}$ and $\mathrm{Cu}^{1 \mathrm{st}} \mathrm{Fe}^{2 \mathrm{nd}}$

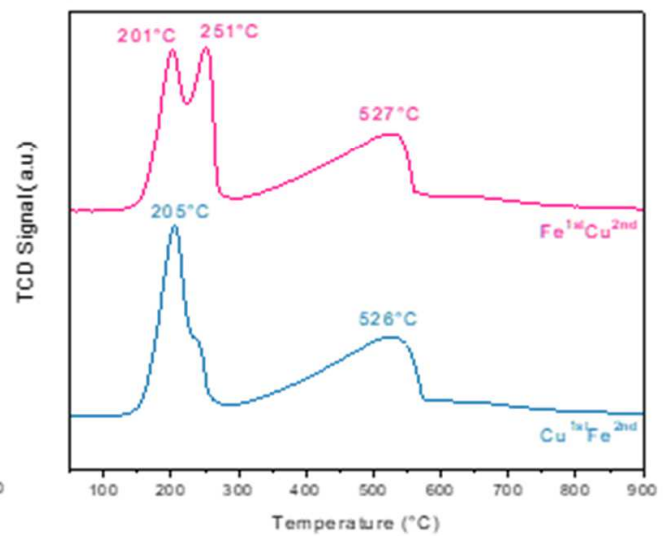

Figure 4. TPR profiles of the catalysts

FT synthesis may involve iron carbide phase [58]. The improved iron reducibility can favor iron carbide formation under the reaction conditions. The reduction of iron oxides and iron carbidisation are therefore, essential for the activation of iron catalysts [10]. $\mathrm{H}_{2}-\mathrm{TPR}$ 
analyzes were performed for all catalysts (Figure 4). The TPR profiles were baselinecorrected. The monometallic Fe-in and Fe-out iron catalysts exhibit similar profiles, with 3 main groups of hydrogen consumption peaks referring to the multistep reduction from hematite to metallic $\mathrm{Fe}$ [10,35]: $\mathrm{Fe}_{2} \mathrm{O}_{3} \rightarrow \mathrm{Fe}_{3} \mathrm{O}_{4} \rightarrow \mathrm{FeO} \rightarrow \mathrm{Fe}$ [37]. The extent of the reduction of metal is defined as the ratio between the actual $\mathrm{H}_{2}$ amount consumed during the $\mathrm{H}_{2}-\mathrm{TPR}$ process (from room temperature to $900{ }^{\circ} \mathrm{C}$ ) and theoretical amount of $\mathrm{H}_{2}$ required for the complete reduction of metal oxides [37]. The TPR peaks of iron catalysts are broad, this may be due to a broad iron particle size distribution and/or metal-support interactions. The first peak can be related to the reduction of $\mathrm{Fe}_{2} \mathrm{O}_{3}$ to $\mathrm{Fe}_{3} \mathrm{O}_{4}\left(\sim 250-420{ }^{\circ} \mathrm{C}\right)[59,60]$, the second peak can be ascribed to the reduction of $\mathrm{Fe}_{3} \mathrm{O}_{4}$ to $\mathrm{FeO}$ and the third peak can be assigned to the reduction of $\mathrm{FeO}$ to $\mathrm{Fe}\left(\sim 600-700{ }^{\circ} \mathrm{C}\right)[10,35,60]$. There is a tail, after $650{ }^{\circ} \mathrm{C}$, due to the gasification of CNTs [5,37]. The copper catalysts $(\mathrm{Cu}$-in and $\mathrm{Cu}$-out) exhibit a broad peak $\left(\sim 100-280{ }^{\circ} \mathrm{C}\right)$, referring to the reduction of $\mathrm{CuO}$ to metallic $\mathrm{Cu}[41,43,60]$ and another large and weak peak referring to the gasification of CNT supports. The $\mathrm{Cu}$-in catalyst exhibited a shoulder in the mean peak $\left(\sim 226^{\circ} \mathrm{C}\right)$, this could be due to the reduction of $\mathrm{CuO}$ to metallic $\mathrm{Cu}$ proceeding through intermediate $\mathrm{Cu}^{+}$species [40,61]. The bimetallic $\mathrm{Cu}^{1 \text { st }} \mathrm{Fe}^{2 \text { nd }}$, $\mathrm{Fe}^{1 \mathrm{st}} \mathrm{Cu}^{2 \text { nd }}, \mathrm{Fe}+\mathrm{Cu}$-in, $\mathrm{Fe}+\mathrm{Cu}$-out catalysts had similar profiles, being a junction of the profiles of iron catalysts and copper catalysts, with two large and separate peaks. The TPR peaks attributed to the reduction to iron metallic phase shift from $615-640{ }^{\circ} \mathrm{C}$ (Figure 4a), in monometallic iron catalysts to $453-535^{\circ} \mathrm{C}$ in the bimetallic counterparts (Figure $4 \mathbf{c}$ and $\mathbf{d}$ ). If we compare the profiles of monometallic iron catalysts with the bimetallic catalysts, the catalyst reduction is accomplished at lower temperatures for the bimetallic catalysts. This suggests that the presence of copper may facilitate the reduction of iron. The $\mathrm{CuO}$ reduction occurs at lower temperatures than the $\mathrm{Fe}_{\mathrm{x}} \mathrm{O}_{\mathrm{y}}$ reduction. This nucleation of copper metal 
nanoparticles can provide $\mathrm{H}_{2}$ dissociation sites and therefore can increase the concentration of atomic hydrogen on the surface of the catalyst, which assists the reduction of iron oxides $[20]$.

The broad peaks at $450-660^{\circ} \mathrm{C}$ can be due to the gasification of CNTs, which usually happens at temperatures higher than $600{ }^{\circ} \mathrm{C}$ [37]. In the profiles of bi-metallic catalysts, the peaks at this temperature range are larger and shifted by 100 to $200{ }^{\circ} \mathrm{C}$ to lower temperatures compared to the monometallic copper catalysts. This suggests that the presence of both iron and copper may lead to the CNT gasification at temperatures below $600{ }^{\circ} \mathrm{C}$. This observation is consistent with the data of Serp et al.[26] who showed that the gasification of the CNTs could be catalyzed by metal nanoparticles.

a) $\mathrm{Fe} 2 \mathrm{p}$ - calcined catalyst

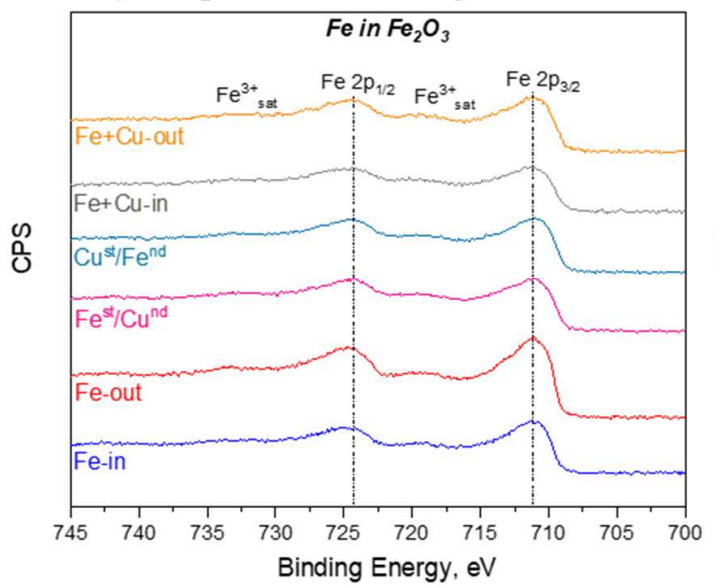

b) $\mathrm{Cu} 2 \mathrm{p}$-calcined catalyst

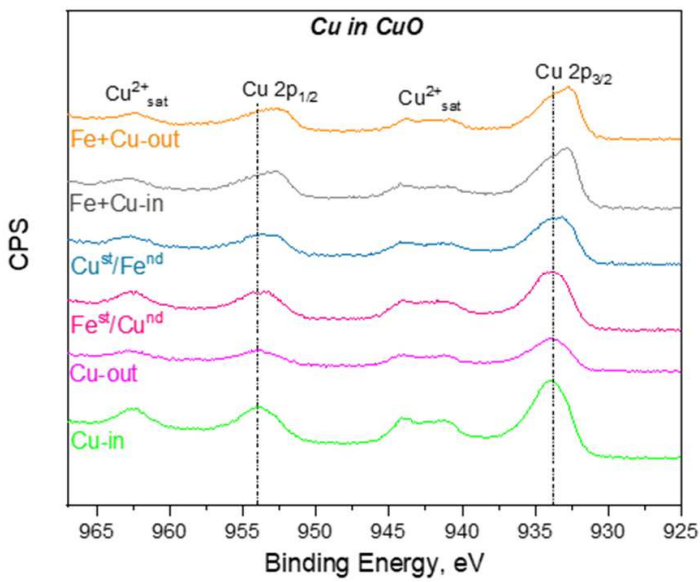

Figure 5. Fe $2 p$ (a) and $\mathrm{Cu} 2 \mathrm{p}(\mathrm{b})$ XPS spectra of the calcined catalysts

Further information about the reducibility of supported iron and copper species can be obtained through the total amount of hydrogen consumed during TPR experiments (Table 1). The bimetallic catalysts show higher hydrogen consumption in the following sequence: $\mathrm{Fe}^{1 \mathrm{st}} \mathrm{Cu}^{2 \text { nd }}>\mathrm{Cu}^{1 \mathrm{st}} \mathrm{Fe}^{2 \text { nd }}>\mathrm{Fe}+\mathrm{Cu}$-in $>\mathrm{Fe}+\mathrm{Cu}$-out, compared to the monometallic catalysts. The 
amount of $\mathrm{H}_{2}$ consumed for Fe-in catalyst was a bit larger when compared to the Fe-out catalyst (Table 1). The theoretical value required for the complete reduction of $\mathrm{Fe}_{2} \mathrm{O}_{3}$ to $\mathrm{Fe}$ is $2.686 \mathrm{mmol} / \mathrm{g}$. This suggests that the extent of reduction for the Fe-in catalyst was $85 \%$ and $79 \%$ for the Fe-out catalyst. This can be attributed to a different interaction of iron oxide with inner surface of $\mathrm{CNT}$. For the $\mathrm{Cu}$-in and $\mathrm{Cu}$-out catalysts, the amount of $\mathrm{H}_{2}$ consumed was 1.9 and $1.8 \mathrm{mmol} / \mathrm{g}$, respectively. Then, the extent of reduction for the $\mathrm{Cu}$-in and $\mathrm{Cu}$-out catalysts is $122 \%$ and $115 \%$, respectively. The TPR peaks were observed at lower temperatures for the $\mathrm{Cu}$-in catalyst than for the $\mathrm{Cu}$-out catalyst. Higher extent of reduction of iron and copper species located inside CNT is consistent with previous results of the group of Pan and Bao [37]. Pan et al. [15] revealed that the reduction of $\mathrm{Fe}_{2} \mathrm{O}_{3}$ particles was facilitated, when the particles are confined within MWCNTs in relation to the particles located on the outside. The reduction was facilitated by narrowing the channels of the CNTs. Not only the location of the nanoparticles, but also the metal loading and dispersion of the nanoparticles may also influence in the extent of reduction. The higher is the metal loading, the higher is the consumption of hydrogen.

We performed conventional ex-situ XPS measurements for the calcined catalysts in order to get information about the chemical states and concentration of $\mathrm{Cu}$ and $\mathrm{Fe}$ on the catalyst surfaces. The XPS spectra in the Fe 2 p region are shown in Figure 5a. The binding energies (BEs) for the $\mathrm{Fe} 2 \mathrm{p}_{3 / 2}$ and $2 \mathrm{p}_{1 / 2}$ main peaks were around 711 and $724.5 \mathrm{eV}$, respectively (Table S5, SM), for all iron containing monometallic and bimetallic catalysts. The peaks for the $\mathrm{Fe} 2 \mathrm{p}_{3 / 2}$ and $\mathrm{Fe} 2 \mathrm{p}_{1 / 2}$ core levels with BEs of $\sim 711$ and $\sim 724.5 \mathrm{eV}$, respectively, combined with the satellite peak at $\sim 719 \mathrm{eV}$, which is characteristic of $\mathrm{Fe}^{3+}$, are related to the $\mathrm{Fe}_{2} \mathrm{O}_{3}[33,36,43,62-64]$. Note that the $\mathrm{Fe}^{3+} 2 \mathrm{p}_{3 / 2}$ peak of $\mathrm{Cu}^{1 \mathrm{st}} \mathrm{Fe}^{2 \mathrm{nd}}$ appears at $711.0 \mathrm{eV}$, which is a little higher in energy than the standard peak at $710.9 \mathrm{eV}$ for $\mathrm{Fe}_{2} \mathrm{O}_{3}$. 
This may indicate the existence of a small amount of $\mathrm{Fe}_{3} \mathrm{O}_{4}$ species in $\mathrm{Cu}^{1 s t} \mathrm{Fe}^{2 \text { nd }}$, since the $\mathrm{Fe}^{3+} 2 \mathrm{p}_{3 / 2}$ peak for $\mathrm{Fe}^{3} \mathrm{O}^{4}$ at $711.4 \mathrm{eV}$ is about $0.5 \mathrm{eV}$ higher than that for $\mathrm{Fe}_{2} \mathrm{O}_{3}$ at $710.9 \mathrm{eV}[5]$.

Table 4. XPS surface concentration of the calcined and used catalysts

\begin{tabular}{|c|c|c|c|c|}
\hline \multicolumn{2}{|l|}{ Sample } & \multirow{2}{*}{$\begin{array}{l}\text { Mass conc., \% } \\
4.8\end{array}$} & \multirow{2}{*}{\begin{tabular}{|l} 
At. conc., $\%$ \\
1.1
\end{tabular}} & \multirow{2}{*}{$\begin{array}{l}\text { XPS At. ratio, \% } \\
\mathrm{Fe} / \mathrm{C}=1.05\end{array}$} \\
\hline Fe-in & Fe $2 p$ & & & \\
\hline Fe-out & $\mathrm{Fe} 2 \mathrm{p}$ & 7.3 & 1.7 & $\mathrm{Fe} / \mathrm{C}=1.61$ \\
\hline $\mathrm{Cu}$-in & $\mathrm{Cu} 2 \mathrm{p}$ & 5.9 & 1.2 & $\mathrm{Cu} / \mathrm{C}=1.23$ \\
\hline $\mathrm{Cu}$-out & $\mathrm{Cu} 2 \mathrm{p}$ & 2.6 & 0.5 & $\mathrm{Cu} / \mathrm{C}=0.46$ \\
\hline \multirow{2}{*}{$\mathrm{Cu}^{1 \mathrm{st}} / \mathrm{Fe}^{2 \mathrm{nd}}$} & Fe $2 p$ & 7.0 & 1.7 & $\mathrm{Fe} / \mathrm{C}=1.66$ \\
\hline & $\mathrm{Cu} 2 \mathrm{p}$ & 4.8 & 1.0 & $\mathrm{Cu} / \mathrm{C}=1.06$ \\
\hline \multirow{2}{*}{$\mathrm{Fe}^{1 \mathrm{st}} / \mathrm{Cu}^{2 \mathrm{nd}}$} & $\mathrm{Fe} 2 \mathrm{p}$ & 5.8 & 1.4 & $\mathrm{Fe} / \mathrm{C}=1.48$ \\
\hline & $\mathrm{Cu} 2 \mathrm{p}$ & 4.9 & 1.0 & $\mathrm{Cu} / \mathrm{C}=1.11$ \\
\hline \multirow{2}{*}{$\mathrm{Fe}+\mathrm{Cu}$-in } & Fe 2p & 5.0 & 1.2 & $\mathrm{Fe} / \mathrm{C}=1.17$ \\
\hline & $\mathrm{Cu} 2 \mathrm{p}$ & 4.5 & 0.9 & $\mathrm{Cu} / \mathrm{C}=0.94$ \\
\hline \multirow{2}{*}{$\mathrm{Fe}+\mathrm{Cu}-$ out } & Fe $2 p$ & 4.8 & 1.1 & $\mathrm{Fe} / \mathrm{C}=1.12$ \\
\hline & $\mathrm{Cu} 2 \mathrm{p}$ & 3.1 & 0.6 & $\mathrm{Cu} / \mathrm{C}=0.67$ \\
\hline \multicolumn{2}{|l|}{ Sample } & Mass conc., \% & At. conc., $\%$ & XPS At. ratio, $\%$ \\
\hline Fe-out used & $\mathrm{Fe} 2 \mathrm{p}$ & 1.6 & 0.4 & $\mathrm{Fe} / \mathrm{C}=0.32$ \\
\hline $\mathrm{Cu}$-in used & $\mathrm{Cu} 2 \mathrm{p}$ & 1.9 & 0.4 & $\mathrm{Cu} / \mathrm{C}=0.34$ \\
\hline $\mathrm{Cu}$-out used & $\mathrm{Cu} 2 \mathrm{p}$ & 0.9 & 0.2 & $\mathrm{Cu} / \mathrm{C}=0.20$ \\
\hline \multirow{2}{*}{$\mathrm{Cu}^{1 \mathrm{st}} / \mathrm{Fe}^{2 \mathrm{nd}}$ used } & Fe $2 p$ & 1.3 & 0.3 & $\mathrm{Fe} / \mathrm{C}=0.42$ \\
\hline & $\mathrm{Cu} 2 \mathrm{p}$ & 1.3 & 0.3 & $\mathrm{Cu} / \mathrm{C}=0.29$ \\
\hline \multirow{2}{*}{$\mathrm{Fe}^{1 \mathrm{st}} / \mathrm{Cu}^{2 \mathrm{nd}}$ used } & $\mathrm{Fe} 2 \mathrm{p}$ & 1.2 & 0.3 & $\mathrm{Fe} / \mathrm{C}=0.29$ \\
\hline & $\mathrm{Cu} 2 \mathrm{p}$ & 1.2 & 0.2 & $\mathrm{Cu} / \mathrm{C}=0.22$ \\
\hline \multirow{2}{*}{$\mathrm{Fe}+\mathrm{Cu}$-out used } & Fe $2 p$ & 1.2 & 0.3 & $\mathrm{Fe} / \mathrm{C}=0.39$ \\
\hline & $\mathrm{Cu} 2 \mathrm{p}$ & 1.6 & 0.3 & $\mathrm{Cu} / \mathrm{C}=0.34$ \\
\hline
\end{tabular}


The BEs of $\mathrm{Cu} 2 \mathrm{p}_{3 / 2}$ and $\mathrm{Cu} 2 \mathrm{p}_{1 / 2}$ were around $933 \mathrm{eV}$ and $953 \mathrm{eV}$, respectively (Figure 5b, Table S5, SM). According to the Moulder et al. [64], the BE values for $\mathrm{Cu}_{2} \mathrm{p}_{3 / 2}$ between 932 and $933 \mathrm{eV}$ indicate the presence of $\mathrm{Cu}_{2} \mathrm{O}$, while the values between 933 and $934 \mathrm{eV}$ suggest $\mathrm{CuO}$ [41]. The standard binding energy for the $\mathrm{Cu} 2 \mathrm{p}_{3 / 2}$ for $\mathrm{Cu}$ in $\mathrm{CuO}$ is 933.6 eV. This is the case for the $\mathrm{Cu}$-in and Cu-out catalysts that show BE of $933.8 \mathrm{eV}$. The $\mathrm{BE}$ values of $\mathrm{Cu} 2 \mathrm{p}_{3 / 2}$ were observed at $932.8 \mathrm{eV}$ and $932.7 \mathrm{eV}$ for the $\mathrm{Fe}+\mathrm{Cu}$-in and $\mathrm{Fe}+\mathrm{Cu}-$ out catalysts and can be attributed to the $\mathrm{Cu}^{+}$species [65], but while the presence of a the strong satellite peak at $\sim 942 \mathrm{eV}$ is characteristic of $\mathrm{Cu}^{2+}$ species [65]. The $\mathrm{Cu}$ KLL Auger peaks (Figure S5, Table S5, SM) have thus been examined for $\mathrm{Fe}+\mathrm{Cu}$-in and $\mathrm{Fe}+\mathrm{Cu}$-out catalysts and showed a main peak with Kinetic Energies (KEs) $917.0 \mathrm{eV}$ and $917.5 \mathrm{eV}$ respectively.

The $\mathrm{Cu} 2 \mathrm{p}$ photopeak $\mathrm{BE}$ along with the $\mathrm{Cu}$ KLL Auger peak KE allows the determination of the modified Auger Parameter (AP') and correspond to $1849.3 \mathrm{eV}$ and $1850.2 \mathrm{eV}$ respectively. The AP' energy for both catalysts is characteristic of $\mathrm{Cu}^{+}$species. This means that both $\mathrm{Cu}$ oxide species are present in this samples, also, the major copper species in the $\mathrm{Fe}+\mathrm{Cu}$-in catalyst are $\mathrm{Cu}^{+}[66]$.

The copper and iron atomic and mass relative concentrations calculated from XPS, are presented in Table 4. The XPS data provide information about $\mathrm{Cu} / \mathrm{Fe}$ ratio on the surface. Rather similar bulk and surface $\mathrm{Cu} / \mathrm{Fe}$ ratios measured by XRF and XPS indicate uniform distribution and similar dispersion of copper and iron in the calcined bimetallic catalysts. 
Table 5. Catalytic results for the catalysts. Reaction conditions: $\mathrm{T}=350^{\circ} \mathrm{C}, 10 \mathrm{bar}, \mathrm{H}_{2} / \mathrm{CO}=$ $1, \mathrm{GHSV}=6.6 \mathrm{~L} / \mathrm{g} \mathrm{h}, \mathrm{t}_{\text {reaction }}=20 \mathrm{~h}$.

\begin{tabular}{|c|c|c|c|c|c|c|c|c|c|c|}
\hline \multirow[b]{2}{*}{ Catalyst } & \multirow[b]{2}{*}{$\begin{array}{l}\text { FTY } \\
10^{-4} \quad(\mathrm{~mol} \\
\left.\mathrm{CO} / \mathrm{g}_{\mathrm{Fe}} \mathrm{s}\right)\end{array}$} & \multirow[b]{2}{*}{$\begin{array}{l}\mathrm{CO} \\
\text { conv } \\
(\%)\end{array}$} & \multirow[b]{2}{*}{$\begin{array}{l}\mathrm{CO}_{2} \\
\text { selec } \\
(\%)\end{array}$} & \multicolumn{5}{|c|}{ Hydrocarbon Selectivity (\%) } & \multirow[b]{2}{*}{$\begin{array}{l}\text { Ratio } \\
\mathrm{CH}_{2}-\mathrm{CH}_{4}=/ \\
\mathrm{CH}_{2}-\mathrm{H}_{4}{ }^{\circ}\end{array}$} & \multirow[b]{2}{*}{$\begin{array}{l}\text { TOF } \\
\left(\mathrm{s}^{-1}\right)\end{array}$} \\
\hline & & & & $\mathrm{CH}_{4}$ & $\begin{array}{l}\text { Olefins } \\
\mathrm{CH}_{2}-\mathrm{CH}_{4}=\end{array}$ & $\begin{array}{l}\text { Paraffins } \\
\mathrm{CH}_{2}-\mathrm{H}_{4}{ }^{\circ}\end{array}$ & $\begin{array}{l}\text { Alcohols } \\
\left(\mathrm{CH}_{3} \mathrm{OH} .\right. \\
\left.\mathrm{C}_{2} \mathrm{H}_{5} \mathrm{OH}\right)\end{array}$ & $\mathrm{C}_{5+}$ & & \\
\hline Fe-in & 2.37 & 53.4 & 44.4 & 19.5 & 26.6 & 15.2 & 0.3 & 38.4 & 1.75 & 1.05 \\
\hline $\mathrm{Fe}$-in $2^{\text {nd }}$ & - & 54.2 & 45.0 & 20.0 & 28.3 & 14.5 & 0.8 & 36.4 & 1.95 & - \\
\hline Fe-out & 1.97 & 19.0 & 29.0 & 19.4 & 21.3 & 11.5 & - & 47.8 & 1.85 & 1.09 \\
\hline $\mathrm{Cu}^{1 \mathrm{st}} \mathrm{Fe}^{2 \mathrm{nd}}$ & 4.05 & 79.9 & 49.5 & 25.7 & 24.9 & 18.9 & 0.4 & 30.1 & 1.32 & 2.47 \\
\hline $\mathrm{Fe}^{1 \mathrm{st}} \mathrm{Cu}^{2 \mathrm{nd}}$ & 3.35 & 50.2 & 42.8 & 20.3 & 24.0 & 14.4 & 0.5 & 40.8 & 1.67 & 1.81 \\
\hline $\mathrm{Fe}+\mathrm{Cu}$-in & 2.47 & 37.7 & 38.7 & 19.9 & 22.0 & 13.8 & 1.8 & 42.5 & 1.59 & - \\
\hline $\mathrm{Fe}+\mathrm{Cu}$-out & 3.16 & 33.0 & 37.2 & 20.3 & 19.4 & 15.4 & 1.9 & 43.0 & 1.26 & - \\
\hline
\end{tabular}

\section{Catalytic performance}

The FT catalytic data for the confined and non-confined catalysts are displayed in Table 5. Methane, light olefins, light paraffins, $\mathrm{C}_{5+}$ hydrocarbons, oxygenates and $\mathrm{CO}_{2}$ were detected as major reaction products. The catalysts exhibit very high selectivity to $\mathrm{CO}_{2}$ (between 29 and $44 \%$ ), which is probably produced by an almost stoichiometric reaction of $\mathrm{CO}$ with the water produced by FT synthesis: $\mathrm{CO}+\mathrm{H}_{2} \mathrm{O}=\mathrm{CO}_{2}+\mathrm{H}_{2}$. At $350{ }^{\circ} \mathrm{C}$, the catalysts show higher selectivity to the $\mathrm{C}_{2}-\mathrm{C}_{4}$ olefins, while the selectivity to the $\mathrm{C}_{5+}$ hydrocarbons was between 30 and $47 \%$. Only trace amounts of oxygenates (methanol and ethanol) were observed. 


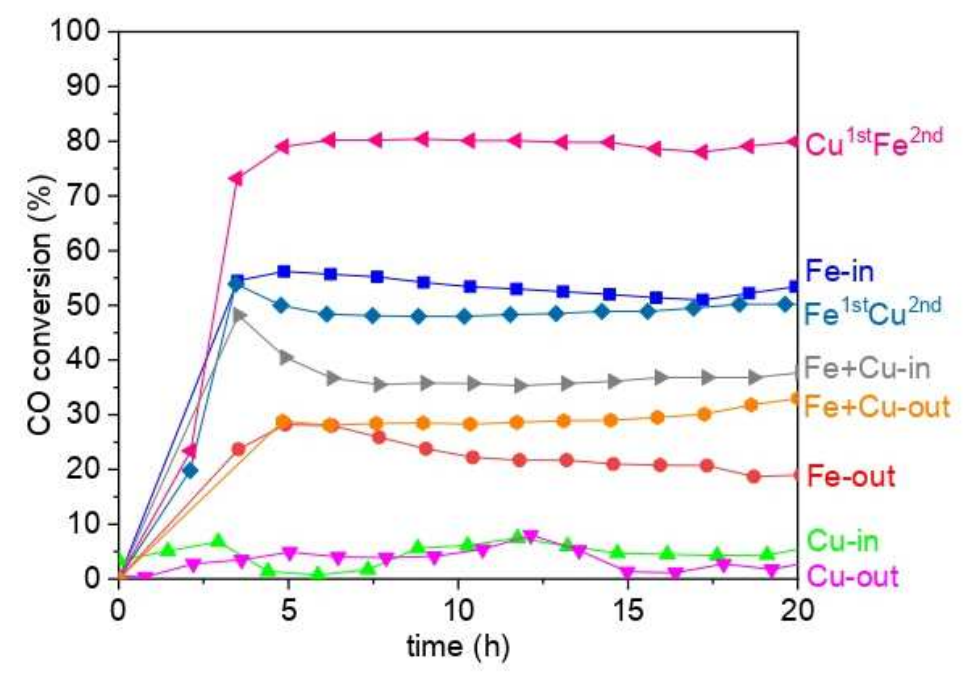

Figure 6. Carbon monoxide conversion over monometallic and bimetallic catalysts as a function of reaction time. Reaction conditions: $\mathrm{H}_{2} / \mathrm{CO}=1, \mathrm{P}=10$ bar, $\mathrm{T}=350^{\circ} \mathrm{C}$

Figure 6 shows the CO conversion over the catalysts during FT synthesis as a function of the reaction time, while Figure S6, SM displays the time-dependent variation of the selectivities. Some variation of the $\mathrm{CO}$ conversion is observed during the first $5 \mathrm{~h}$ of reaction. But after that, the values become stable. The copper catalysts showed extremely low activity under these conditions; the $\mathrm{CO}$ conversion was well below $5 \%$. The conversion of monometallic iron catalysts strongly depends on the localization of iron. Interestingly, when iron nanoparticles are located inside CNT, the reaction rate was $20 \%$ higher compared to the Fe-out catalysts with iron species situated outside of CNT. These results are consistent with previous works showing higher activity of the catalysts containing iron nanoparticles inside CNT [10,14,16,48,67,68]. Previously, Pan et al.[15] studied the effect of confinement on the synthesis of FT by comparing external iron (Fe-out) and internal iron (Fe-in). In the present work, the behavior was similar to the work of Pan et al. [15]. The Fe-in catalyst shows almost $80 \%$ of the Fe particles within CNTs, and its counterpart Fe-out present $\sim 93 \%$ of $\mathrm{Fe}$ 
particles out of channels. However, different to Pan et al. [15] who obtained favored CO conversion and formation of long-chain hydrocarbons with the confined catalyst Fe-in, in the present work, only the $\mathrm{CO}$ conversion was favored by the confinement of Fe particles, whereas the formation of $\mathrm{C}_{5+}$ hydrocarbons was favored in the Fe-out catalyst (Table 5). Higher activity of Fe-in could be attributed to the confinement inside CNTs, which may prevent iron particles from severe sintering and facilitate the reduction of iron oxide to form iron carbides [15].

On the bimetallic catalysts, the $\mathrm{CO}$ conversion strongly depends on the catalyst preparation method. Moderate catalytic activity is observed over the catalyst prepared by coimpregnation over both closed and open CNT. The bimetallic catalysts prepared by sequential impregnation exhibit higher catalytic performance. The $\mathrm{Cu}^{1 \text { st }} \mathrm{Fe}^{\text {2nd }}$ catalyst prepared using first impregnation with copper followed impregnation with iron showed the higher FT reaction rate. Only relatively small effect of the promotion and catalyst preparation method was observed on the hydrocarbon selectivity.

Water Gas Shift (WGS) is an important side reaction that occurs during FTS, over iron catalysts. Table 5 suggests that the WGS-activity was significantly lower than the FTactivity for the non-confined $\mathrm{Fe}$ monometallic catalyst. In the other hand, for bimetallic catalysts, the higher selectivity of $\mathrm{CO}_{2}$ may be due to the higher rate of WGS reaction, and also to higher $\mathrm{CO}$ conversion.

The chain growth probability was in the range of 0.48 to 0.59 . According to the Anderson-Schulz- Flory (ASF) distribution, this value of alpha is related to the maximum selectivity for $\mathrm{C}_{2}-\mathrm{C}_{4}$ range: $\sim 58 \%$. Higher $\mathrm{C}_{2}-\mathrm{C}_{4}$ selectivity of $\sim 44 \%$ was obtained for the 
$\mathrm{Cu}^{1 \text { st }} \mathrm{Fe}^{2 \text { nd }}$ catalyst. The selectivities to alpha and internal $\mathrm{C}_{4}$ olefins are given in Table 7 ,

SM. The selectivity effects are consistent with previous report by Coville et al [69], who also observed the effect of copper on the catalytic activity and not on the selectivity over iron catalysts supported by CNT.

a) Fe-out used and Fe-in used

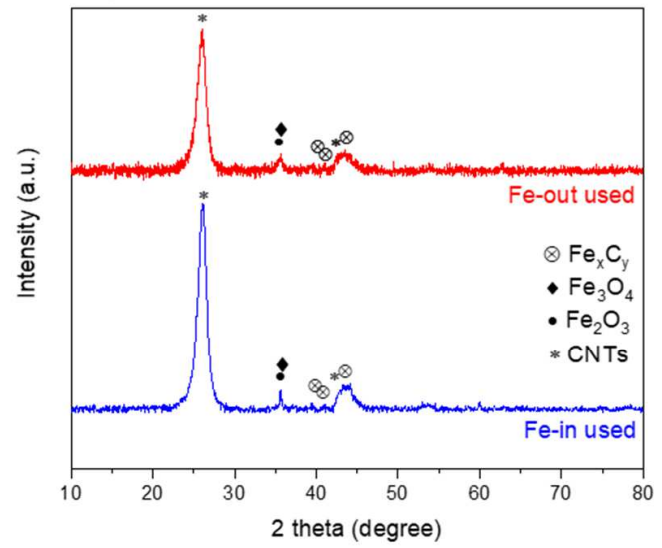

c) $\mathrm{Fe}+\mathrm{Cu}$-out used and $\mathrm{Fe}+\mathrm{Cu}$-in used

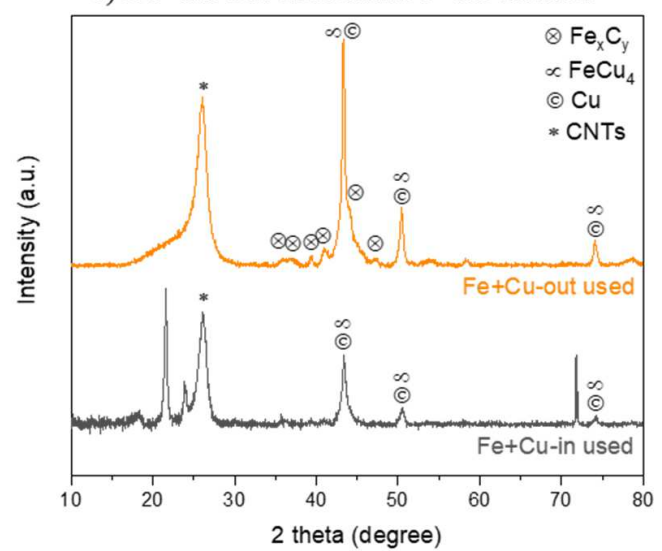

b) Cu-out used and $\mathrm{Cu}$-in used

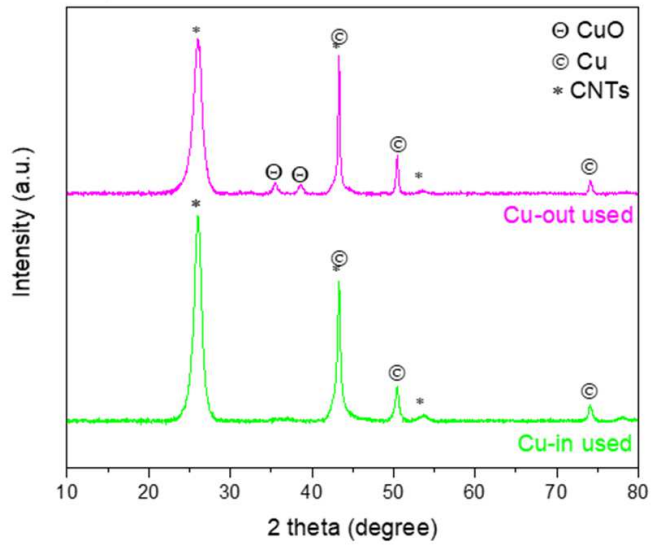

d) $\mathrm{Cu}^{1 \text { st }} \mathrm{Fe}^{2 \text { nd }}$ used and $\mathrm{Fe}^{1 \text { st }} \mathrm{Cu}^{2 \text { nd }}$ used

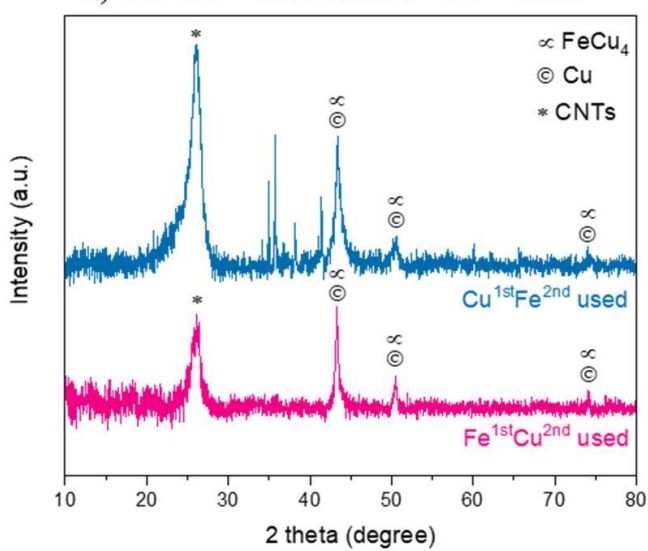

Figure 7. XRD patterns of the used catalysts

\section{Characterization of spent catalysts}

The XRD profiles of the catalysts after reaction are displayed in Figure 7. Both Fein used and $\mathrm{Fe}$-out used catalysts present a broad peak around $44^{\circ}$ related to iron carbide [36,68]. No XRD peaks attributed to metallic iron were detected. 

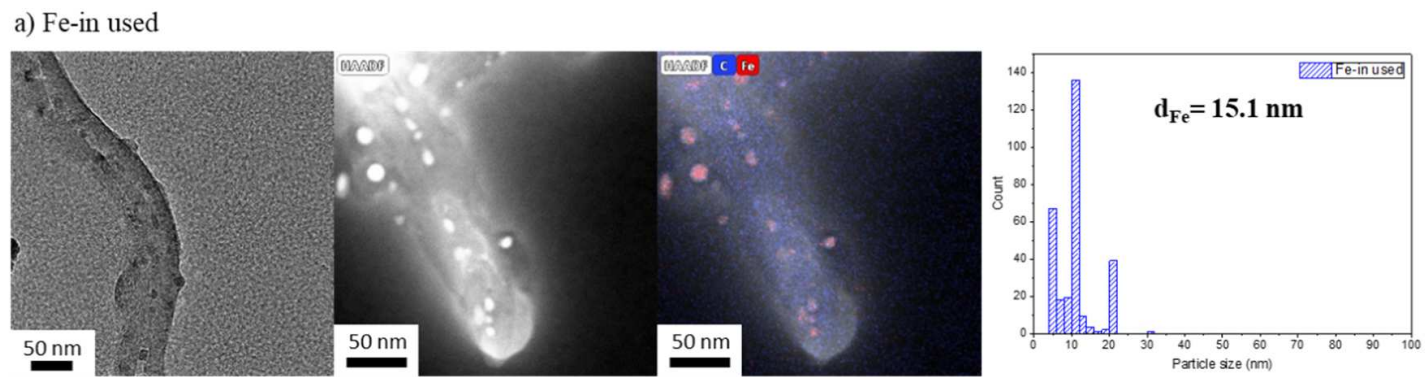

b) Cu-in used
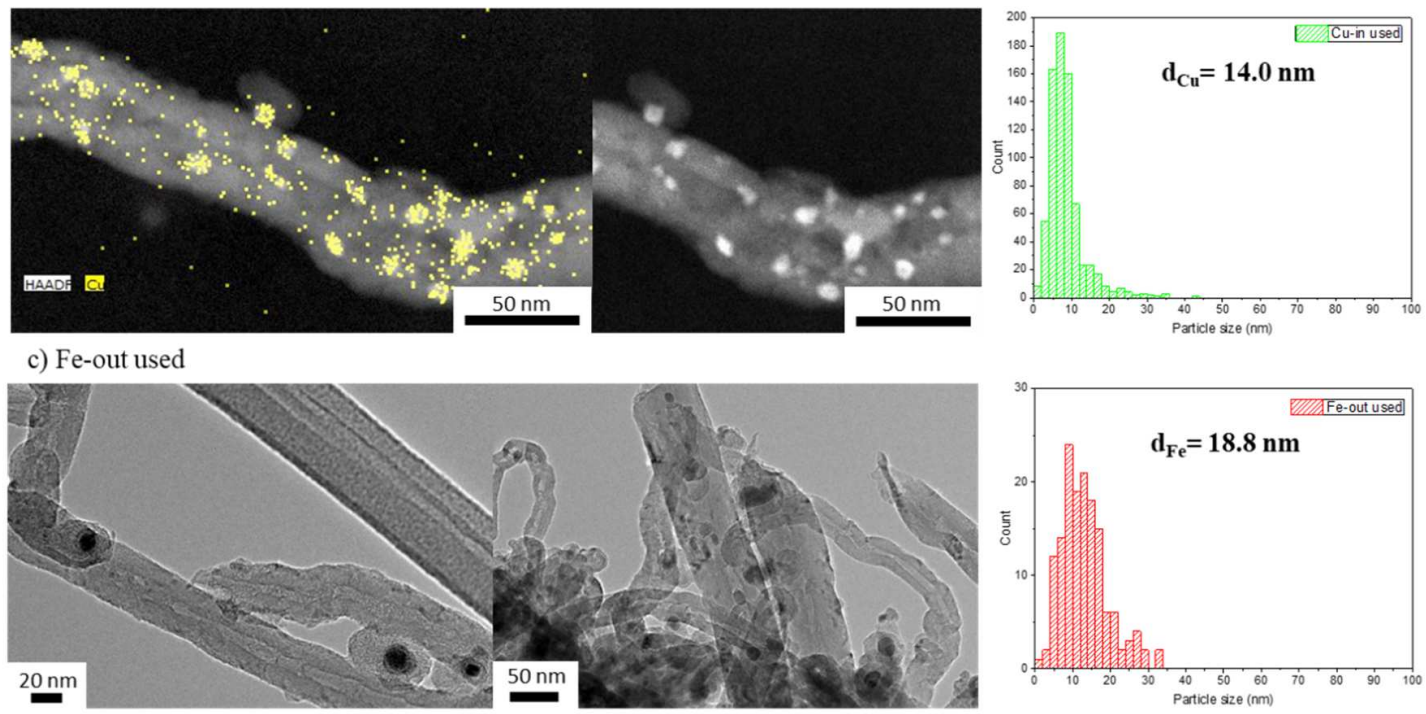

d) $\mathrm{Fe}^{1 \mathrm{st}} \mathrm{Cu}^{\text {2nd }}$ used
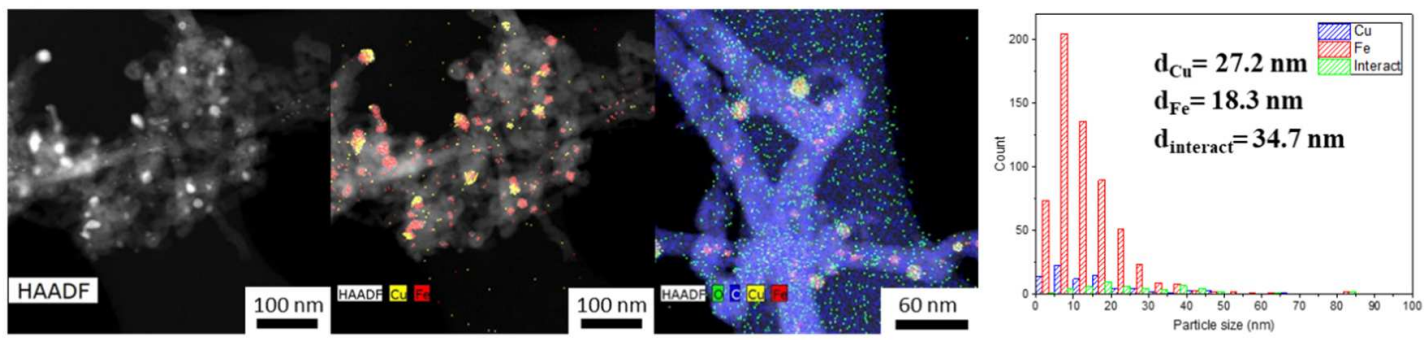

e) $\mathrm{Cu}^{1 \mathrm{st}} \mathrm{Fe}^{2 \mathrm{nd}}$ used
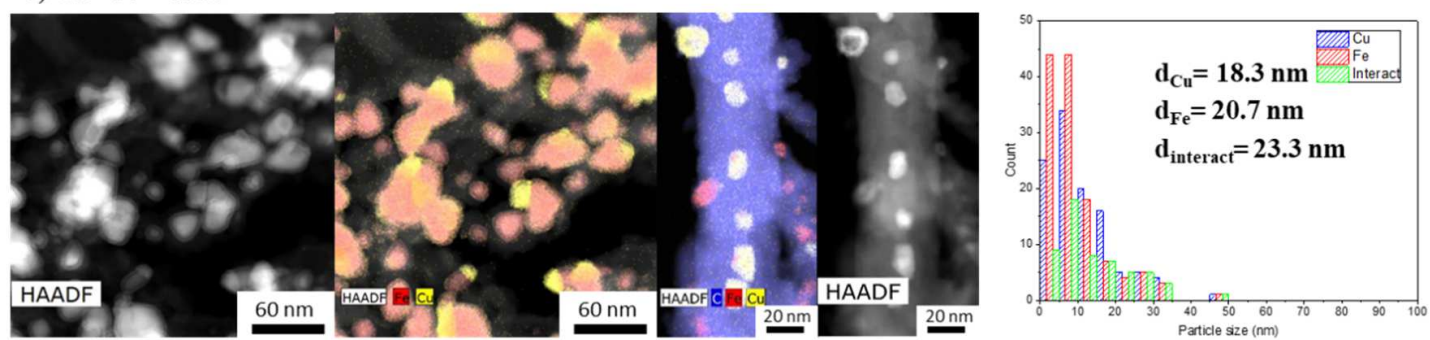

Figure 8. TEM micrographs and histograms of particle size distribution of the used catalysts. 
This broad peak may correspond to the superposition of the most intense diffraction peaks of several iron carbides, most likely $\mathrm{Fe}_{5} \mathrm{C}_{2}$ (Hägg-carbide) and $\mathrm{Fe}_{3} \mathrm{C}$ (cementite) $[16,68]$. The formation of iron carbides occurs as result of interaction of metallic iron with carbon coming from the dissociation of $\mathrm{CO}$ at high temperatures [16]. Both iron carbides have been considered active in FT synthesis. Higher concentration of iron carbide could lead to a much higher FT reaction rate $[16,68,70]$. Note that iron carbide crystallite sizes determination and even the precise identification of specific carbide phases from the XRD patterns are not possible because of the overlapping of the peaks and their broad shape [35]. The Hägg carbide is generally acknowledged as active phase for FT synthesis [36,71].

The XRD patterns of used $\mathrm{Cu}$-in and $\mathrm{Cu}$-out catalysts (Figure 7) show metallic $\mathrm{Cu}$ and $\mathrm{CuO}$ tenorite. Note that the copper oxide was not present in the used $\mathrm{Cu}$-in sample, when the $\mathrm{Cu}$ particles were confined in CNTs. The confinement therefore prevents oxidation of the metal particles. The XRD patterns of used $\mathrm{Fe}+\mathrm{Cu}$-in and $\mathrm{Fe}+\mathrm{Cu}$-out showed the metallic $\mathrm{Cu}$, $\mathrm{FeCu}_{4}$ alloy and $\mathrm{Hägg}$-carbide- $\mathrm{Fe}_{5} \mathrm{C}_{2}$ phases. The peaks at $43.3^{\circ}, 50.4^{\circ}$, and $74.1^{\circ}$ in the $\mathrm{XRD}$ patterns of used $\mathrm{Fe}+\mathrm{Cu}$-in and $\mathrm{Fe}^{1 \mathrm{st}} \mathrm{Cu}^{2 \text { nd }}$, and can be assigned to (llll 111$),\left(\begin{array}{lll}2 & 0 & 0\end{array}\right)$, and (2 220$)$ reflections of cubic metallic copper $[33,40,43,61]$.

The crystallinity of Fe/CNT was also evaluated using Raman spectroscopy. Table S4, SM shows further increase in the $\mathbf{I}_{\mathbf{D}} / \mathbf{I}_{\mathbf{G}}$ ratio after conducting FT synthesis. The higher decrease in CNT disordering and a higher concentration of defects are observed in the $\mathrm{Fe}^{1 \mathrm{st}} \mathrm{Cu}^{2 \mathrm{nd}}$ and $\mathrm{Cu}^{1 \mathrm{st}} \mathrm{Fe}^{2 \mathrm{nd}}$ prepared during the sequential two-step impregnation.

Figure 8 shows the TEM micrographs of the used catalysts and relevant particle size distribution. The TEM images of the Fe-out spent catalyst reveal that some of the iron carbide particles were covered by a carbon layer [3,70]. This covering layer is due to carbon 
deposition during reaction, which is favored at low $\mathrm{H}_{2} / \mathrm{CO}$ ratios and high temperatures [36]. The TEM analysis of the used catalyst after conducting FT reaction also exhibit a large number of defects (Figure S4, SM). These results are consistent with the Raman data and indicate destruction of the CNT structure after the second impregnation. The effect is even more pronounced after exposing the catalysts to FT reaction.

The TEM images for the Fe-in used catalyst display iron particles with the average size of around $16 \mathrm{~nm}$ with a broad particle size distribution. For the Fe-out used catalyst, the particle size distribution is also broad with the average size of $19.0 \mathrm{~nm}$. As could be observed in Table 2, for all the catalysts, the particle sizes after reaction were larger than before reaction, except for the $\mathrm{Cu}$ particles in $\mathrm{Cu}^{1 \text { st }} \mathrm{Fe}^{2 \text { nd }}$ catalyst.

a) Fe $2 p$ - used catalysts

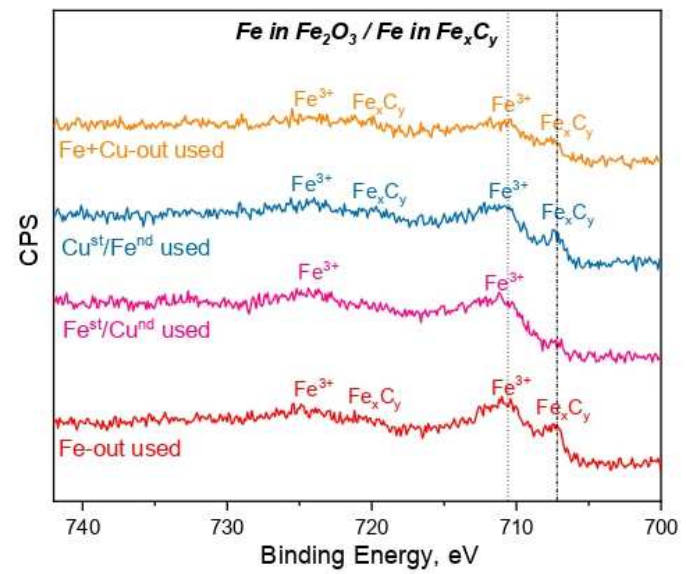

b) $\mathrm{Cu} 2 \mathrm{p}$ - used catalysts

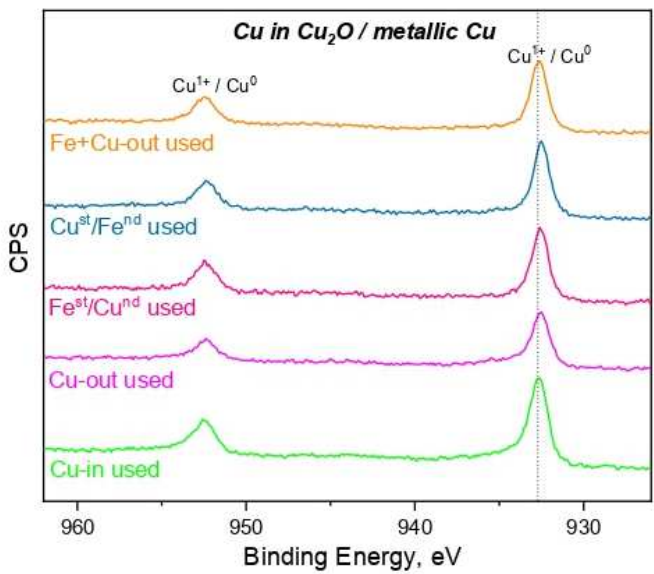

Figure 9. $\mathrm{Fe} 2 \mathrm{p}$ (a) and $\mathrm{Cu} 2 \mathrm{p}$ (b) XPS spectra of the used catalysts

In the Fe-in catalyst, iron particle size increases from $8.8 \mathrm{~nm}$ to $16.1 \mathrm{~nm}$ after the reaction and seems to be limited by CNT inner diameter. The inner diameters of CNT were evaluated in the range from 8.4 to $9.9 \mathrm{~nm}$ using TEM analysis (Table S3, SM). Note that 
growth of iron nanoparticle can result in their elongated shape and can also expand to some extent the CNT inner channels. For comparison, the size of the outside particles in Fe-out grew from $13.7 \mathrm{~nm}$ to $19.0 \mathrm{~nm}$ after the reaction tests (Table 2). This indicates that particle sintering was effectively prevented inside CNTs under the reaction conditions due to the spatial restriction of the CNT channels [16]. STEM-EDX analysis shows that the distribution of iron nanoparticles between inner CNT channels and outer surface does not change very much after conducting the catalytic reaction (Table 3). In the used bimetallic catalysts, significant modification of the distribution of copper and iron nanoparticles between inner channels and outer surface of CNT and reduction in the number of interacting copper and iron nanoparticles were observed. The fraction of interacting nanoparticles is getting clearly higher in $\mathrm{Cu}^{1 \mathrm{st}} \mathrm{Fe}^{2 \text { nd }}$ sample compared to the $\mathrm{Fe}^{1 \mathrm{st}} \mathrm{Cu} 2^{\text {nd }}$ counterpart.

The ex-situ XPS spectra of the used catalyst are displayed in Figure 9. In addition to hematite, a broad shoulder with the binding energy of $707.3 \mathrm{eV}$ assignable to iron carbide [72,73] was detected. The $\mathrm{Cu}$ Auger spectra and calculation of the Auger parameter (Figure S7, SM) show the presence of mostly $\mathrm{Cu}^{+}$species. This is consistent with the formation of iron carbide during catalyst activation and FT synthesis. Iron carbide in the used catalysts was also observed by XRD. A major decrease in the relative $\mathrm{Fe} / \mathrm{C}$ and $\mathrm{Cu} / \mathrm{C}$ atomic concentrations is observed after the catalytic tests (Table 4). This is indicative of sintering and increase in the size of both iron and copper nanoparticles under the reaction conditions. The sintering of copper and iron species during FT reaction was also observed by TEM (Table 2). 
a) $\mathrm{Cu} 2 \mathrm{p}-\mathrm{Fe}^{1 \mathrm{st}} \mathrm{Cu}^{2 \mathrm{nd}}$

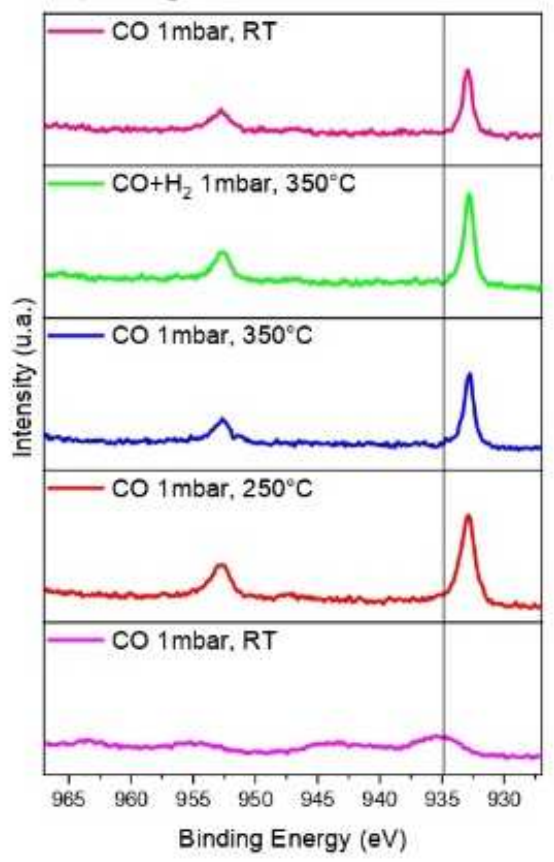

b) $\mathrm{Fe} 2 \mathrm{p}-\mathrm{Fe}^{1 \mathrm{st}} \mathrm{Cu}^{2 \mathrm{nd}}$

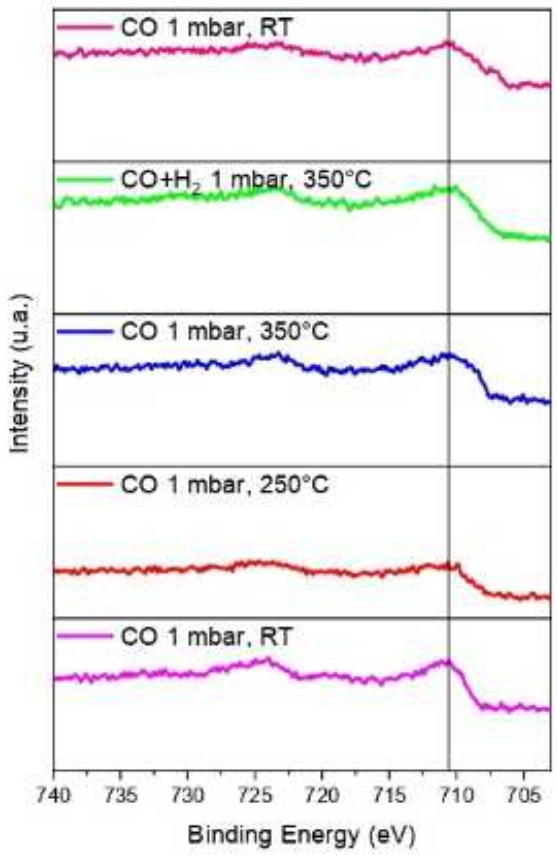

Figure 10. $\mathrm{Cu} 2 \mathrm{p}$ (a) and $\mathrm{Fe} 2 \mathrm{p}$ (b) NAP-XPS spectra of the $\mathrm{Fe}^{1 \mathrm{st}} \mathrm{Cu}^{2 \text { nd }}$ catalyst In-situ investigation of the catalyst sub-surface layer by NAP-XPS Iron carbide and copper metallic nanoparticles are sensitive to the presence of air and can be oxidized after their withdrawal for the reactor. The nanoparticle surface can be even more affected by oxidation. In order to obtain information about the evolution of surface and subsurface layer in the bimetallic copper-iron catalysts in $\mathrm{CO}$ or syngas at different temperatures, we conducted NAP-XPS experiments following the experimental procedure shown in Figure S8, SM. The freshly calcined samples were first loaded into the NAP-XPS spectrometer and exposed to $\mathrm{CO}$ at room temperature. Then, the temperature was increased subsequently from room temperature to $250^{\circ} \mathrm{C}$ and to $350^{\circ} \mathrm{C}$. After the exposure to $350^{\circ} \mathrm{C}$ in $\mathrm{CO}$, the sample 
was cooled down to $180^{\circ} \mathrm{C}$ for $1 \mathrm{~h}$. Then, $\mathrm{CO}$ was switched to syngas $\left(\mathrm{H}_{2} / \mathrm{CO}=1\right)$ and the temperature was increased to $350^{\circ} \mathrm{C}$. The sample was maintained in syngas at this temperature and then cooled back again to room temperature. At different steps of the in-situ catalyst treatment under about 1 mbar of $\mathrm{CO}$ or syngas, the position, shape and intensity of $\mathrm{Fe} 2 \mathrm{p}, \mathrm{Cu} 2 \mathrm{p}$ and $\mathrm{C} 1 \mathrm{~s}$ peaks were thoroughly analyzed by XPS.
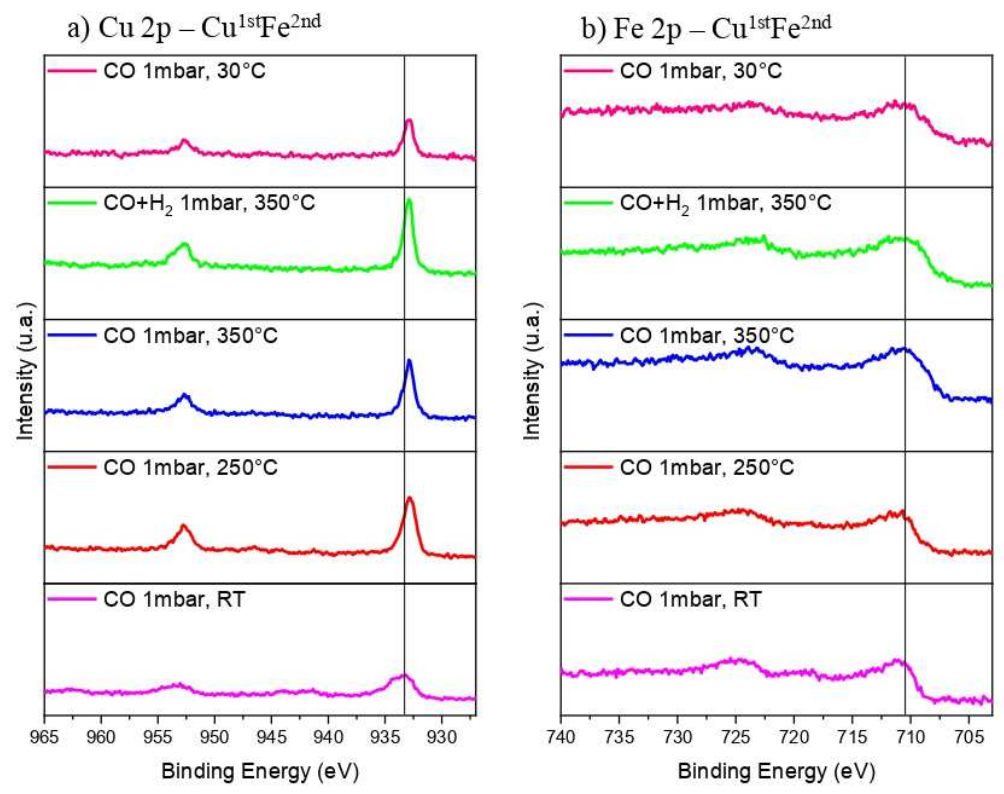

Figure 11. $\mathrm{Cu} 2 \mathrm{p}$ (a) and $\mathrm{Fe} 2 \mathrm{p}$ (b) NAP-XPS spectra of the $\mathrm{Cu}^{1 \mathrm{st}} \mathrm{Fe}^{2 \text { nd }}$ catalyst

The Fe $2 p$ and $\mathrm{Cu} 2 p$ NAP-XPS spectra of the $\mathrm{Fe}^{1 \mathrm{st}} \mathrm{Cu}^{2 \mathrm{nd}}, \mathrm{Cu}^{1 \mathrm{st}} \mathrm{Fe}^{2 \mathrm{nd}}$ and $\mathrm{Fe}-\mathrm{Cu}$ - in catalysts are presented in Figures 10, 11 and S9, SM. Similar to the conventional XPS, the Cu2p NAPXPS spectra of calcined catalysts (Figures 10a and 11 a) suggest the possible presence of $\mathrm{CuO}$ and $\mathrm{Cu}_{2} \mathrm{O}$, which were detected by the peak at 934-935 eV[41,64,65], spin-orbital splitting and satellites. The Fe 2p NAP-XPS spectra (Figures 10b and 11b) of the calcined catalysts also exhibit the peaks at $\sim 711.0 \mathrm{eV}\left(\mathrm{Fe} 2 \mathrm{p}_{3 / 2}\right)$ and $\sim 724.6 \mathrm{eV}\left(\mathrm{Fe} 2 \mathrm{p}_{1 / 2}\right)$ with a shakeup satellite peak at $\sim 719.2 \mathrm{eV}$. The spectra and binding energies distinctly indicate the 
presence of $\mathrm{Fe}^{3+}$ species[74]. This observation is consistent with the results of XRD and conventional XPS and indicates the presence of iron and copper oxides in the fresh samples. After the temperature increase in $\mathrm{CO}$ to 250 and then to $350{ }^{\circ} \mathrm{C}$, the $\mathrm{Cu} 2 \mathrm{p}$ peaks (Figures 10a and 11a) shift to lower energy. The low energy shift is indicative of copper reduction. The copper metal phase was identified in the XPS spectra by binding energies $(\mathrm{Cu} 2 \mathrm{p} 3 / 2=932.9 \mathrm{eV}[75])$, spin-orbital splitting and line shape. The exposure of the catalysts to $\mathrm{CO}$ also leads to a broad shoulder in the Fe 2p XPS region with the binding energy of 707 $\mathrm{eV}$ assignable to iron carbide $[72,73]$. Further treatment of the catalysts in syngas results in an increase in the intensity of this feature and correspondingly a higher fraction of iron carbide. The NAP-XPS results for both $\mathrm{Fe}^{1 \mathrm{st}} \mathrm{Cu}^{2 \mathrm{nd}}$ and $\mathrm{Cu}^{1 \mathrm{st}} \mathrm{Fe}^{2 \mathrm{nd}}$ suggest the almost complete reduction of copper oxide to the metallic state in $\mathrm{CO}$ at $250^{\circ} \mathrm{C}$, while only a relatively small amount of iron carbide has been produced even after extended catalyst treatment in $\mathrm{CO}$ at $350^{\circ} \mathrm{C}$. The oxidation states of both copper and iron do not change after subsequent cooling down the catalysts to room temperature.

Since the catalysts were supported by CNT, we consider that the intensity of C $1 \mathrm{~s}$ peak does not change during the experiments. The $\mathrm{C} 1 \mathrm{~s}$ intensity was used therefore, as a reference in order to evaluate the variation of relative intensity of Fe $2 p$ XPS peaks during the treatments in $\mathrm{CO}$ and syngas at high temperatures. The relative intensities and atomic concentrations (normalized to carbon) measured by NAP-XPS are displayed in Table 6. Both $\mathrm{Fe} / \mathrm{C}$ and $\mathrm{Cu} / \mathrm{C}$ ratios are higher in $\mathrm{Cu}^{1 s t} \mathrm{Fe}^{2 \text { nd }}$ sample compared to $\mathrm{Fe}^{1 \mathrm{st}} \mathrm{Cu}^{2 \text { nd }}$. This is consistent with the conventional XPS results (Table 4) and also indicates a smaller size of copper and iron nanoparticles in the $\mathrm{Cu}^{1 \mathrm{st}} \mathrm{Fe}^{2 \mathrm{nd}}$ sample measured by TEM (Table 2).

The increase in the temperature results in the decrease in both $\mathrm{Fe} / \mathrm{C}$ and $\mathrm{Cu} / \mathrm{C}$ atomic ratios for both catalysts. This decrease may correspond to lower concentration of metals in the 
subsurface layer due to the nanoparticle sintering. The decrease in the surface concentration of copper in $\mathrm{CO}$ between $250^{\circ} \mathrm{C}$ and $350^{\circ} \mathrm{C}$ is much more pronounced compared to iron (Table 6 and Table S6, SM). Interestingly, this temperature range also corresponds to copper reduction.

Table 6. Relative intensities of peaks and atomic concentrations measured in the presence of hydrogen and syngas in the NAP-XPS experiments

\begin{tabular}{|l|l|l|l|l|}
\hline \multirow{5}{*}{ Sample } & Gas & Temperature, ${ }^{\circ} \mathrm{C}$ & Fe/C atom ratio, \% & Cu/C atom ratio, \% \\
\hline \multirow{5}{*}{$\mathrm{Fe}^{1 \mathrm{st}} \mathrm{Cu}^{\text {2nd }}$} & $\mathrm{CO}$ & $\mathrm{RT}$ & 2.32 & 1.74 \\
\cline { 2 - 6 } & $\mathrm{CO}$ & 250 & 2.46 & 2.46 \\
\cline { 2 - 6 } & $\mathrm{CO}$ & 350 & 1.83 & 0.76 \\
\cline { 2 - 6 } & $\mathrm{CO}+\mathrm{H}_{2}$ & 350 & 2.17 & 0.87 \\
\cline { 2 - 6 } & $\mathrm{CO}$ & 40 & 1.61 & 0.65 \\
\hline \multirow{5}{*}{$\mathrm{Cu}^{1 \mathrm{st}} \mathrm{Fe}^{2 \text { 2nd }}$} & $\mathrm{CO}$ & $\mathrm{RT}$ & 3.39 & 1.75 \\
\cline { 2 - 6 } & $\mathrm{CO}$ & 250 & 3.08 & 1.83 \\
\cline { 2 - 6 } & $\mathrm{CO}$ & 350 & 2.67 & 1.11 \\
\cline { 2 - 5 } & $\mathrm{CO}+\mathrm{H}_{2}$ & 350 & 3.49 & 0.77 \\
\cline { 2 - 5 } & $\mathrm{CO}$ & 30 & 2.53 & \\
\hline
\end{tabular}

This suggests that both copper migration and sintering proceed during the reduction. The $\mathrm{Cu} / \mathrm{C}$ ratio also drops more than three-times in $\mathrm{Fe}^{1 \mathrm{st}} \mathrm{Cu}^{2 \text { nd }}$, while a much smaller decrease was observed for the $\mathrm{Cu}^{1 \mathrm{st}} \mathrm{Fe}^{2 \mathrm{nd}}$ sample. These results are consistent with TEM, which indicates a more significant increase in the copper particle size in $\mathrm{Fe}^{1 \mathrm{st}} \mathrm{Cu}^{\text {2nd }}$ (Table 2) and major migration of copper nanoparticles from inside to outside of CNT (Table 3). The copper particle size increases from 11.4 to $27.1 \mathrm{~nm}$ in $\mathrm{Fe}^{1 \mathrm{st}} \mathrm{Cu}^{2 \text { nd }}$ and the fraction of copper outside 
$\mathrm{CNT}$ increases from 66.4 to $88.1 \%$. Exposure of the $\mathrm{Cu}^{1 s t} \mathrm{Fe}^{2 \text { nd }}$ catalyst to syngas at $350^{\circ} \mathrm{C}$ leads to the increase in the intensity of both $\mathrm{Fe}$ and $\mathrm{Cu}$ XPS signals, which may correspond to migration and restructuring of the metallic and carbide species during the FT reaction. Cooling down the catalysts after exposure to syngas at $350^{\circ} \mathrm{C}$ to $30-40^{\circ} \mathrm{C}$ is accompanied by a decrease in $\mathrm{Fe} / \mathrm{C}$ and $\mathrm{Cu} / \mathrm{C}$ ratio (Table 6). TEM-EDS shows (Figure 8) the presence of a shell of carbon around metal nanoparticles in the spent catalysts. It can be suggested that after the exposure to syngas this carbon shell could reduce the intensity of the XPS signal for both iron and copper.

Mobility, nanoconfinement, and interaction of copper and iron nanoparticles in CNT and their influence on the catalytic performance

The catalyst characterization indicates several important phenomena occurring with iron and iron-copper catalysts supported over CNT during the catalyst synthesis, activation and catalytic reaction. First, we must emphasize the major differences between monometallic and bimetallic catalysts. In the iron or copper monometallic catalysts, if CNTs are closed, more than $90 \%$ of metal nanoparticles are located on the CNT outer surface. Only a small fraction of metal nanoparticles (about 10\%) can possibly penetrate the CNT channels, because of the presence of defects. When the CNTs were open by treatment with concentrated nitric acid, introduction of either iron or copper results in the preferential localization of these species inside carbon nanotubes. TEM-EDX shows that about $80 \%$ of these metals are confined in the CNTs (Table 3). Note that the localization of iron or copper species in the monometallic copper or iron catalysts is relatively stable. Most of these species remain confined inside CNTs even after extensive exposure to syngas under FT reaction conditions. The fraction of 
iron nanoparticles inside CNT slightly decreases to $72 \%$ in the used catalysts, while for copper it drops to $58 \%$.

The situation is very different for the bimetallic iron-copper samples prepared by sequential impregnation. TEM-EDX identified three types of nanoparticles in these samples: (i) monometallic iron nanoparticles, (ii) monometallic copper nanoparticles, (iii) interacting copper-iron nanoparticles, which are situated in close contact with each other. Note that we did not see bimetallic iron-copper nanoparticles in both samples. This is probably due to a very low mutual solubility [23] of copper and iron. In the calcined catalysts prepared by sequential impregnation, most iron, copper and interacting nanoparticles are localized outside CNTs. The fraction of the nanoparticles outside CNT is always higher than 50\% (Table 3). The $\mathrm{Fe}^{1 \mathrm{st}} \mathrm{Cu}^{2 \text { nd }}$ and $\mathrm{Cu}^{1 \mathrm{st}} \mathrm{Fe}^{2 \text { nd }}$ samples are prepared from $\mathrm{Fe}$-in and $\mathrm{Cu}$-in samples by sequential impregnation with respectively copper and iron. This suggests significant migration of the metal species introduced in the first impregnation step, which were initially confined inside CNTs. Note that we did not observe this migration in the monometallic catalysts. Our results suggest that the order of CNT impregnation with copper and iron does not affect to any noticeable extent the distribution of metal species between the channels and outer surface of CNTs.

There can be three driving forces for the mobility of metal nanoparticles from the inner to the outer CNT surface. The first driving force is due to the interaction of copper and iron nanoparticles and nanotubes. For CNTs, the contact to the metal can be either an end-contact [76], that involves bonds at the interface, or can be a side-contact, that involves a weakly bonded interface with the outer or inner surface of the tube. Yu [77] et al. used density functional theory to calculate the interactions of Fe inside and outside CNTs and showed that 
for several Fe species, the bonding with the outside wall of the CNT could be stronger than that with the inside wall.

Second, the diffusion of metal particles to the outer surface of CNT may facilitate their sintering and thus minimization of surface energy. Indeed, inside CNT the nanoparticle sintering can be limited by the pore diameter. These steric constrains do not exist anymore, when the nanoparticles have moved to the CNT outer surface. Previously, diffusion of metal nanoparticles in porous supports to the outer surface during the exposure to the higher temperature and chemical agents has been observed in a number of publications.

The third driving force of particle diffusion can be the interaction between copper metallic and iron carbide nanoparticles. Because of less significant steric constrains, the strong interaction and proximity of copper and iron nanoparticles could be much easier to reach on the CNT outer surface than inside CNT channels.

The exposure of the catalysts prepared by sequential impregnation to $\mathrm{CO}$ and syngas further modifies the distribution of different types of metal nanoparticles (Table 3). Interestingly, the fraction of interacting nanoparticles in both $\mathrm{Cu}^{1 \mathrm{st}} \mathrm{Fe}^{\text {nd }}$ and $\mathrm{Fe}^{1 \mathrm{st}} \mathrm{Cu}^{2 \text { nd }}$ decreases after conducting FT synthesis. NAP-XPS suggests that noticeable migration of copper proceeds during its reduction to metallic state in $\mathrm{CO}$ at $250-350^{\circ} \mathrm{C}$, while the migration of iron was less significant (Table 6). At the same time, we observed using TEM and Raman spectroscopy a decrease in CNT ordering and appearance of defects after the second impregnation step with copper or iron (Figure S4, SM). Note that even exposure of the Fein catalyst to acidified water $(\mathrm{pH}=3)$ without a metal precursor also damages the CNT structure. Exposure of the catalysts to FT reaction conditions further damages the CNT structure. At the same time, the impregnation of Fe-in with water with $\mathrm{pH}$ similar to that of the copper nitrate solution does not affect the catalytic performance (Table 5). This suggests 
that the dispersion and localization of iron nanoparticles have not been much affected by the second impregnation with water. This also suggests that the migration of iron and copper is not only due to the presence of the defects in the CNT structure, but is also related to the reduction/oxidation processes in the presence of $\mathrm{CO}$ and syngas and interaction between copper and iron.

NAP-XPS is indicative of further migration of iron and copper, which occurs in syngas and generally leads to some increase in their dispersion (Table 6). Our results also show that confinement, migration and interaction of copper and iron affect the catalytic performance in FT synthesis. The catalytic activity of monometallic copper catalyst with copper localized either inside (Cu-in) or outside (Cu-out) $\mathrm{CNT}$ was very low compared to the iron counterparts. The catalytic performance of the bimetallic iron-copper or monometallic iron catalysts can be therefore attributed to the surface sites associated with iron and not with copper. In agreement with numerous previous reports[58], the catalytic activity of iron catalysts in high-temperature FT synthesis has been attributed to the iron carbide phase, which has been detected in the spent catalyst by XRD (Figure 7). At the same time, copper can be considered as a promoter, which enhances the activity of the iron active phase.

The iron time yield (FTY) and turnover frequency (TOF) are presented in Table 5. The calculated TOF values provided important information about the intrinsic activity of surface sites in the monometallic iron and bimetallic iron-copper catalysts. First, we observed that the intrinsic activity of iron sites (TOF) is not much affected by nanoconfinement. Indeed, TOFs calculated for Fe-in and Fe-out are almost the same (Table 5). The effect of nanoconfinement is therefore mostly relevant to the enhancement of iron dispersion inside CNT. The size of iron nanoparticles encapsulated inside CNT is smaller in Fe-in than Fe-out 
sample with nanoparticles located on the outer surface. Moreover, they remain much smaller in Fe-in after the catalytic test (Table 2). This result is consistent with the recent report by $\mathrm{Gu}[10]$.

Second, the promotion with copper results in a noticeable increase in TOF from 1.05-1.09 $\mathrm{s}^{-}$ ${ }^{1}$ in the monometallic iron catalysts to $1.81-2.47 \mathrm{~s}^{-1}$ in the bimetallic samples. Note that the higher TOF is observed in the $\mathrm{Cu}^{1 \text { st }} \mathrm{Fe}^{2 \text { nd }}$ catalyst. Characterization of this catalyst using STEM-EDX (Table 3) suggests the presence of a higher fraction of interacting iron copper nanoparticles than in $\mathrm{Fe}^{1 \mathrm{st}} \mathrm{Cu}^{2 \text { nd }}\left(23.7 \%\right.$ in $\mathrm{Cu}^{1 \mathrm{st}} \mathrm{Fe}^{2 \text { nd }}$ versus $\left.7.8 \% \mathrm{Fe}^{1 \mathrm{st}} \mathrm{Cu}^{2 \text { nd }}\right)$. The catalytic performance in FT synthesis is an interplay of several phenomena occurring in monometallic iron and bimetallic copper-iron catalysts. First, the FT reaction rate depends on iron particle size and the number of active sites. Smaller iron nanoparticle size is generally obtained when iron species are localized inside CNT. The second parameter is the extent of iron carbidisation, which is also a function of iron particle size and promoter. Finally, the interaction between iron carbide and copper nanoparticles results in the increase of instinct activity of active sites. Table 5 shows that the FT reaction rate (FTY) slightly increases when copper and iron are added together inside CNT compared to the monometallic Fe-in sample from 2.37 to $2.47 \times 10^{-4}$ mol $\mathrm{CO} \mathrm{g}_{\mathrm{Fe}}^{-1} \mathrm{~s}^{-1}$. This is consistent with previous reports, which emphasize the importance of copper and iron interaction $[19,33]$ for the enhanced catalytic performance of iron-copper bimetallic catalysts.

Thus, copper seems to be both a structuring and an electronic promoter. On the one hand, copper improves iron reducibility and carbidisation compared to the monometallic iron catalysts. The facilitated iron reduction can be related to the hydrogen spillover effect on $\mathrm{Cu}$, meanwhile producing a large number of active sites and then, increasing the $\mathrm{CO}$ conversion[20]. On the other hand, a close localization of copper to iron results in a higher 
intrinsic activity of iron surface sites (TOF). The addition of $\mathrm{Cu}$ in iron based catalyst can increase the selectivity to $\mathrm{CO}_{2}$ due to the positive effect of copper on the WGS reaction. [78] The geometry of $\mathrm{Fe}$ and $\mathrm{Cu}$ particles in interaction can play a crucial role in catalytic performance. $\mathrm{Lu}$ et al.[79] performed a DFT calculation on a $\mathrm{Cu}^{0}-\chi-\mathrm{Fe}_{5} \mathrm{C}_{2}$ surface model to elucidate the synergistic interactions of $\mathrm{Cu}^{0}-\chi-\mathrm{Fe}_{5} \mathrm{C}_{2}$ catalysts for selective $\mathrm{CO}$ hydrogenation to higher alcohols. The authors showed that the atomic arrangement of the active sites can play a significant effect on the binding strength of the adsorbates. Their calculation results showed that only $\mathrm{CO}$ prefers the adsorption at the interface of $\mathrm{Cu}^{0}-\chi-\mathrm{Fe}_{5} \mathrm{C}_{2}, \mathrm{CH}_{\mathrm{x}}(\mathrm{x}=1-3)$ and $\mathrm{H}$ species prefer the adsorption at the top of Fe sites on $\mathrm{Cu}^{0}-\chi-\mathrm{Fe}_{5} \mathrm{C}_{2}$ surface. $\mathrm{The}^{\mathrm{CH}} \mathrm{H}_{\mathrm{x}}(\mathrm{x}=1-$

3) dissociation, hydrogenation and coupling to $\mathrm{C}_{2}$-hydrocarbons occur preferentially at the Fe sites on $\mathrm{Cu}^{0}-\chi-\mathrm{Fe}_{5} \mathrm{C}_{2}$.

The amount of iron sites with enhanced activity situated in close proximity to copper nanoparticles depends on the catalyst preparation method and evolves during catalyst activation and reaction. Surprisingly, both copper and iron species remain extremely mobile in bimetallic catalysts, while in the monometallic catalysts, copper and iron nanoparticles seem to be relatively immobile within CNT during catalyst preparation, activation and reaction.

\section{Conclusion}

Remarkable mobility of both iron and copper species was observed in the bimetallic ironcopper catalysts. This mobility seems to be enhanced by the emergence of numerous defects in CNT caused by the second impregnation with acid solutions and results in the enhanced iron-copper interaction. The catalytic performance of bimetallic iron-copper catalysts is 
affected by the localization of iron species within CNT and their interaction with copper localized in the proximity. The number of these iron active sites interacting with copper is not much affected by the initial localization of these two species deposited over CNT during the impregnation but by the migration of iron and copper during the catalyst calcination, activation and catalytic reaction.

In the monometallic iron catalysts, the nanoconfinement results in localization and relative stability of iron nanoparticles inside CNT. The catalytic performance of monometallic iron catalysts is principally a function of iron dispersion, while the intrinsic activity of iron sites is not much influenced by the nanoconfinement inside CNT.

\section{Acknowledgements}

The authors thank Dr Joëlle Thuriot, Olivier Gardoll, Johann Jezequel, Laurence Burylo and Martine Trentesaux for the help with elementary analysis, XRF, TPR, BET, XRD and Raman measurements. The authors are thankful to the CERIC-ERIC Consortium for the access to the NAP-XPS experimental facilities. The authors acknowledge financial support from ISITE Université Lille Nord-Europe (Nanoconfinement project). 


\section{References}

[1] H.M. Torres Galvis, K.P. de Jong, Catalysts for Production of Lower Olefins from Synthesis Gas: A Review, ACS Catal. 3 (2013) 2130-2149. https://doi.org/10.1021/cs4003436.

[2] V. V. Ordomsky, Y. Luo, B. Gu, A. Carvalho, P.A. Chernavskii, K. Cheng, A.Y. Khodakov, Soldering of iron catalysts for direct synthesis of light olefins from syngas under mild reaction conditions, ACS Catal. 7 (2017) 6445-6452. https://doi.org/10.1021/acscatal.7b01307.

[3] A.S.M. Ismail, M. Casavola, B. Liu, A. Gloter, T.W. Van Deelen, M. Versluijs, J.D. Meeldijk, O. Stéphan, K.P. De Jong, F.M.F. De Groot, Atomic-Scale Investigation of the Structural and Electronic Properties of Cobalt-Iron Bimetallic Fischer-Tropsch Catalysts, ACS Catal. 9 (2019) 7998-8011. https://doi.org/10.1021/acscatal.8b04334.

[4] J. Xie, H.M. Torres Galvis, A.C.J. Koeken, A. Kirilin, A.I. Dugulan, M. Ruitenbeek, K.P. De Jong, Size and promoter effects on stability of carbon-nanofiber-supported iron-based Fischer-Tropsch catalysts, ACS Catal. 6 (2016) 4017-4024. https://doi.org/10.1021/acscatal.6b00321.

[5] J. Lu, L. Yang, B. Xu, Q. Wu, D. Zhang, S. Yuan, Y. Zhai, X. Wang, Y. Fan, Z. Hu, Promotion effects of nitrogen doping into carbon nanotubes on supported iron fischertropsch catalysts for lower olefins, ACS Catal. 4 (2014) 613-621. https://doi.org/10.1021/cs400931z.

[6] V. Subramanian, K. Cheng, C. Lancelot, S. Heyte, S. Paul, S. Moldovan, O. Ersen, M. Marinova, V. V. Ordomsky, A.Y. Khodakov, Nanoreactors: An Efficient Tool to Control the Chain-Length Distribution in Fischer-Tropsch Synthesis, ACS Catal. 6 (2016) 1785-1792. https://doi.org/10.1021/acscatal.5b01596. 
[7] Y. Chen, J. Wei, M.S. Duyar, V. V. Ordomsky, A.Y. Khodakov, J. Liu, Carbon-based catalysts for Fischer-Tropsch synthesis, Chem. Soc. Rev. 50 (2021) 2337-2366. https://doi.org/10.1039/D0CS00905A.

[8] H.J. Schulte, B. Graf, W. Xia, M. Muhler, Nitrogen- and Oxygen-Functionalized Multiwalled Carbon Nanotubes Used as Support in Iron-Catalyzed, High-Temperature Fischer-Tropsch Synthesis, ChemCatChem. $4 \quad$ (2012) 350-355. https://doi.org/10.1002/cctc.201100275.

[9] L.M. Chew, W. Xia, H. Düdder, P. Weide, H. Ruland, M. Muhler, On the role of the stability of functional groups in multi-walled carbon nanotubes applied as support in iron-based high-temperature Fischer-Tropsch synthesis, Catal. Today. 270 (2016) 8592. https://doi.org/10.1016/j.cattod.2015.09.023.

[10] B. Gu, S. He, D. V. Peron, D.R. Strossi Pedrolo, S. Moldovan, M.C. Ribeiro, B. Lobato, P.A. Chernavskii, V. V. Ordomsky, A.Y. Khodakov, Synergy of nanoconfinement and promotion in the design of efficient supported iron catalysts for direct olefin synthesis from syngas, J. Catal. 376 (2019) 1-16. https://doi.org/10.1016/j.jcat.2019.06.035.

[11] Z. Sun, B. Sun, M. Qiao, J. Wei, Q. Yue, C. Wang, Y. Deng, S. Kaliaguine, D. Zhao, A general chelate-assisted co-assembly to metallic nanoparticles- incorporated ordered mesoporous carbon catalysts for fischer-tropsch synthesis, J. Am. Chem. Soc. 134 (2012) 17653-17660. https://doi.org/10.1021/ja306913x.

[12] V.P. Santos, T.A. Wezendonk, J.J.D. Jaén, A.I. Dugulan, M.A. Nasalevich, H.-U. Islam, A. Chojecki, S. Sartipi, X. Sun, A.A. Hakeem, A.C.J. Koeken, M. Ruitenbeek, T. Davidian, G.R. Meima, G. Sankar, F. Kapteijn, M. Makkee, J. Gascon, Metal organic framework-mediated synthesis of highly active and stable Fischer-Tropsch 
catalysts, Nat. Commun. 6 (2015) 6451. https://doi.org/10.1038/ncomms7451.

[13] X. Yang, W. Wang, L. Wu, X. Li, T. Wang, S. Liao, Effect of confinement of $\mathrm{TiO}_{2}$ nanotubes over the Ru nanoparticles on Fischer-Tropsch synthesis, Appl. Catal. A Gen. 526 (2016) 45-52. https://doi.org/10.1016/j.apcata.2016.07.021.

[14] J. Xiao, X. Pan, S. Guo, P. Ren, X. Bao, Toward fundamentals of confined catalysis in carbon nanotubes, J. Am. Chem. Soc. 137 (2015) 477-482. https://doi.org/10.1021/ja511498s.

[15] X. Pan, X. Bao, The effects of confinement inside carbon nanotubes on catalysis, Acc. Chem. Res. 44 (2011) 553-562. https://doi.org/10.1021/ar100160t.

[16] W. Chen, Z. Fan, X. Pan, X. Bao, Effect of confinement in carbon nanotubes on the activity of Fischer-Tropsch iron catalyst, J. Am. Chem. Soc. 130 (2008) 9414-9419. https://doi.org/10.1021/ja8008192.

[17] V.R.R. Pendyala, G. Jacobs, M.K. Gnanamani, Y. Hu, A. MacLennan, B.H. Davis, Selectivity control of $\mathrm{Cu}$ promoted iron-based Fischer-Tropsch catalyst by tuning the oxidation state of $\mathrm{Cu}$ to mimic K, Appl. Catal. A Gen. 495 (2015) 45-53. https://doi.org/10.1016/j.apcata.2015.01.027.

[18] P.A. Chernavskii, V.O. Kazak, G. V. Pankina, Y.D. Perfiliev, T. Li, M. Virginie, A.Y. Khodakov, Influence of copper and potassium on the structure and carbidisation of supported iron catalysts for Fischer-Tropsch synthesis, Catal. Sci. Technol. 7 (2017) 2325-2334. https://doi.org/10.1039/c6cy02676a.

[19] Z.H. Chonco, L. Lodya, M. Claeys, E. Van Steen, Copper ferrites: A model for investigating the role of copper in the dynamic iron-based Fischer-Tropsch catalyst, J. Catal. 308 (2013) 363-373. https://doi.org/10.1016/j.jcat.2013.08.012.

[20] D. Peña, L. Jensen, A. Cognigni, R. Myrstad, T. Neumayer, W. van Beek, M. Rønning, 
The Effect of Copper Loading on Iron Carbide Formation and Surface Species in IronBased Fischer-Tropsch Synthesis Catalysts, ChemCatChem. 10 (2018) 1300-1312. https://doi.org/10.1002/cctc.201701673.

[21] X. Sun, X. Liu, J. Liu, Y. He, J. Yin, C. Song, Z. Lv, Y. Bai, Y.W. Li, Y. Yang, X.D. Wen, Elucidation of The Influence of $\mathrm{Cu}$ Promoter on Carburization Prior to IronBased Fischer-Tropsch Synthesis: an In situ X-Ray Diffraction Study, ChemCatChem. 11 (2019) 715-723. https://doi.org/10.1002/cctc.201801706.

[22] H. Xiong, M. Moyo, M.A.M. Motchelaho, L.L. Jewell, N.J. Coville, Fischer-Tropsch synthesis over model iron catalysts supported on carbon spheres: The effect of iron precursor, support pretreatment, catalyst preparation method and promoters, Appl. Catal. A Gen. 388 (2010) 168-178. https://doi.org/10.1016/j.apcata.2010.08.039.

[23] H.T. Luk, C. Mondelli, S. Mitchell, S. Siol, J.A. Stewart, D. Curulla Ferré, J. PérezRamírez, Role of Carbonaceous Supports and Potassium Promoter on Higher Alcohols Synthesis over Copper-Iron Catalysts, ACS Catal. 8 (2018) 9604-9618. https://doi.org/10.1021/acscatal.8b02714.

[24] B. Gu, D. V. Peron, A.J. Barrios, M. Bahri, O. Ersen, M. Vorokhta, B. Šmíd, D. Banerjee, M. Virginie, E. Marceau, R. Wojcieszak, V. V. Ordomsky, A.Y. Khodakov, Mobility and versatility of the liquid bismuth promoter in the working iron catalysts for light olefin synthesis from syngas, Chem. Sci. 11 (2020) 6167-6182. https://doi.org/10.1039/d0sc01600d.

[25] A.J. Barrios, B. Gu, Y. Luo, D. V Peron, P.A. Chernavskii, M. Virginie, R. Wojcieszak, J.W. Thybaut, V. V Ordomsky, A.Y. Khodakov, N.D. Zelinsky, Identification of efficient promoters and selectivity trends in high temperature FischerTropsch synthesis over supported iron catalysts, Appl. Catal. B Environ. 273 (2020) 
119028. https://doi.org/10.1016/j.apcatb.2020.119028.

[26] P. Serp, M. Corrias, P. Kalck, Carbon nanotubes and nanofibers in catalysis, Appl. Catal. A Gen. 253 (2003) 337-358. https://doi.org/10.1016/S0926-860X(03)00549-0.

[27] X. Pan, Z. Fan, W. Chen, Y. Ding, H. Luo, X. Bao, Enhanced ethanol production inside carbon-nanotube reactors containing catalytic particles, Nat. Mater. 6 (2007) 507-511. https://doi.org/10.1038/nmat1916.

[28] B. Gu, C. Zhou, S. He, S. Moldovan, P.A. Chernavskii, V. V. Ordomsky, A.Y. Khodakov, Size and promoter effects on iron nanoparticles confined in carbon nanotubes and their catalytic performance in light olefin synthesis from syngas, Catal. Today. (2019). https://doi.org/10.1016/j.cattod.2019.05.054.

[29] Z. Yang, X. Pan, J. Wang, X. Bao, FeN particles confined inside CNT for light olefin synthesis from syngas : Effects of Mn and K additives, Catal. Today. 186 (2012) 121127. https://doi.org/10.1016/j.cattod.2011.11.034.

[30] Z. Yang, J. Qian, A. Yu, B. Pan, Singlet oxygen mediated iron-based Fenton-like catalysis under nanoconfinement, Proc. Natl. Acad. Sci. U. S. A. 116 (2019) 66596664. https://doi.org/10.1073/pnas.1819382116.

[31] F. (Feng) Tao, Design of an in-house ambient pressure AP-XPS using a bench-top Xray source and the surface chemistry of ceria under reaction conditions, Chem. Commun. 48 (2012) 3812. https://doi.org/10.1039/c2cc17715c.

[32] P.B. Kowalczuk, J. Drzymala, Physical meaning of the Sauter mean diameter of spherical particulate matter, Part. Sci. Technol. 34 (2016) 645-647. https://doi.org/10.1080/02726351.2015.1099582.

[33] S. He, W. Wang, Z. Shen, G. Li, J. Kang, Z. Liu, G.-C. Wang, Q. Zhang, Y. Wang, Carbon nanotube-supported bimetallic $\mathrm{Cu}-\mathrm{Fe}$ catalysts for syngas conversion to higher 
alcohols, Mol. Catal. 479 (2019) 110610. https://doi.org/10.1016/j.mcat.2019.110610.

[34] Z. Chen, Z. Guan, M. Li, Q. Yang, C. Li, Enhancement of the performance of a platinum nanocatalyst confined within carbon nanotubes for asymmetric hydrogenation, Angew. Chemie - Int. Ed. 50 (2011) 4913-4917. https://doi.org/10.1002/anie.201006870.

[35] B. Gu, V. V. Ordomsky, M. Bahri, O. Ersen, P.A. Chernavskii, D. Filimonov, A.Y. Khodakov, Effects of the promotion with bismuth and lead on direct synthesis of light olefins from syngas over carbon nanotube supported iron catalysts, Appl. Catal. B Environ. 234 (2018) 153-166. https://doi.org/10.1016/j.apcatb.2018.04.025.

[36] Y. Cheng, J. Lin, K. Xu, H. Wang, X. Yao, Y. Pei, S. Yan, M. Qiao, B. Zong, FischerTropsch Synthesis to Lower Olefins over Potassium-Promoted Reduced Graphene Oxide Supported Iron Catalysts, ACS Catal. 6 (2016) 389-399. https://doi.org/10.1021/acscatal.5b02024.

[37] R.M.M. Abbaslou, J. Soltan, A.K. Dalai, Effects of nanotubes pore size on the catalytic performances of iron catalysts supported on carbon nanotubes for FischerTropsch synthesis, Appl. Catal. A Gen. 379 (2010) 129-134. https://doi.org/10.1016/j.apcata.2010.03.006.

[38] V. V. Ordomsky, B. Legras, K. Cheng, S. Paul, A.Y. Khodakov, The role of carbon atoms of supported iron carbides in Fischer-Tropsch synthesis, Catal. Sci. Technol. 5 (2015) 1433-1437. https://doi.org/10.1039/c4cy01631a.

[39] A. Chinthakuntla, K. Venkateswara Rao, C. Ashok, Kv. Rao, C. Shilpa Chakra, Structural Analysis of $\mathrm{CuO}$ Nanomaterials prepared by Novel Microwave Assisted Method, J. Atoms Mol. 4 (2014) 803-806. www.jamonline.in.

[40] S. Xiao, Y. Zhang, P. Gao, L. Zhong, X. Li, Z. Zhang, H. Wang, W. Wei, Y. Sun, 
Highly efficient $\mathrm{Cu}$-based catalysts via hydrotalcite-like precursors for $\mathrm{CO}_{2}$ hydrogenation to methanol, Catal. Today. 281 (2017) 327-336. https://doi.org/10.1016/j.cattod.2016.02.004.

[41] D. Zhao, C.M. Tu, X.J. Hu, N. Zhang, Notable in situ surface transformation of $\mathrm{Cu}_{2} \mathrm{O}$ nanomaterials leads to dramatic activity enhancement for $\mathrm{CO}$ oxidation, RSC Adv. 7 (2017) 37596-37603. https://doi.org/10.1039/c7ra05950g.

[42] S. Suresh, S. Karthikeyan, K. Jayamoorthy, FTIR and multivariate analysis to study the effect of bulk and nano copper oxide on peanut plant leaves, J. Sci. Adv. Mater. Devices. 1 (2016) 343-350. https://doi.org/10.1016/j.jsamd.2016.08.004.

[43] L. Yang, J. He, Q. Zhang, Y. Wang, Copper-catalyzed propylene epoxidation by oxygen: Significant promoting effect of vanadium on unsupported copper catalyst, J. Catal. 276 (2010) 76-84. https://doi.org/10.1016/j.jcat.2010.09.002.

[44] L. Feng, C. Zhang, G. Gao, D. Cui, Facile synthesis of hollow $\mathrm{Cu}_{2} \mathrm{O}$ octahedral and spherical nanocrystals and their morphology-dependent photocatalytic properties, Nanoscale Res. Lett. 7 (2012) 1. https://doi.org/10.1186/1556-276X-7-276.

[45] P.Ganesan, H.K.Kuo, A.Saavedra, R.J. De Angelis, Particle size distribution function of supported metal catalysts by X-ray diffraction, J. Catal. 52 (1978) 310-320. https://doi.org/10.1016/0021-9517(78)90145-8.

[46] C. Wang, X. Pan, X. Bao, Direct production of light olefins from syngas over a carbon nanotube confined iron catalyst, Chinese Sci. Bull. 55 (2010) 1117-1119. https://doi.org/10.1007/s11434-010-0076-8.

[47] Q. Cheng, Y. Tian, S. Lyu, N. Zhao, K. Ma, T. Ding, Z. Jiang, L. Wang, J. Zhang, L. Zheng, F. Gao, L. Dong, N. Tsubaki, X. Li, Confined small-sized cobalt catalysts stimulate carbon-chain growth reversely by modifying ASF law of Fischer-Tropsch 
synthesis, Nat. Commun. 9 (2018) 3250. https://doi.org/10.1038/s41467-018-057558.

[48] W. Chen, X. Pan, X. Bao, Tuning of redox properties of iron and iron oxides via encapsulation within carbon nanotubes, J. Am. Chem. Soc. 129 (2007) 7421-7426. https://doi.org/10.1021/ja0713072.

[49] H. Ramaraj, J. Madiga, H. Elangovan, P. Haridoss, C.P. Sharma, Homogenization for Dispersion and Reduction in Length of Carbon Nanotubes, Trans. Indian Inst. Met. 70 (2017) 2629-2639. https://doi.org/10.1007/s12666-017-1123-9.

[50] R. Arrigo, R. Teresi, C. Gambarotti, F. Parisi, G. Lazzara, N.T. Dintcheva, Sonicationinduced modification of carbon nanotubes: Effect on the rheological and thermooxidative behaviour of polymer-based nanocomposites, Materials (Basel). 11 (2018) 1-14. https://doi.org/10.3390/ma11030383.

[51] H. Rennhofer, B. Zanghellini, Dispersion state and damage of carbon nanotubes and carbon nanofibers by ultrasonic dispersion: A review, Nanomaterials. 11 (2021). https://doi.org/10.3390/nano11061469.

[52] A. Sesis, M. Hodnett, G. Memoli, A.J. Wain, I. Jurewicz, A.B. Dalton, J.D. Carey, G. Hinds, Influence of Acoustic Cavitation on the Controlled Ultrasonic Dispersion of Carbon Nanotubes, J. Phys. Chem. B. 117 (2013) 15141-15150. https://doi.org/10.1021/jp410041y.

[53] H.M. Heise, R. Kuckuk, A.K. Ojha, A. Srivastava, V. Srivastava, B.P. Asthana, Characterisation of carbonaceous materials using Raman spectroscopy: A comparison of carbon nanotube filters, single- And multi-walled nanotubes, graphitised porous carbon and graphite, J. Raman Spectrosc. $40 \quad$ (2009) 344-353. https://doi.org/10.1002/jrs.2120. 
[54] V.L. Kuznetsov, S.N. Bokova-Sirosh, S.I. Moseenkov, A. V. Ishchenko, D. V. Krasnikov, M.A. Kazakova, A.I. Romanenko, E.N. Tkachev, E.D. Obraztsova, Raman spectra for characterization of defective CVD multi-walled carbon nanotubes, Phys. $\begin{array}{llllll}\text { Status } & \text { Solidi } & \text { Basic } & \text { Res. } & 251 & \text { (2014) }\end{array}$ https://doi.org/10.1002/pssb.201451195.

[55] R. Xu, Z. Tan, G. Fan, G. Ji, D.B. Xiong, Q. Guo, Y. Su, Z. Li, D. Zhang, Highstrength CNT/Al-Zn-Mg-Cu composites with improved ductility achieved by flake powder metallurgy via elemental alloying, Compos. Part A Appl. Sci. Manuf. 111 (2018) 1-11. https://doi.org/10.1016/j.compositesa.2018.05.012.

[56] S. Costa, E. Borowiak-Palen, M. Kruszyńska, A. Bachmatiuk, R.J. Kaleńczuk, Characterization of carbon nanotubes by Raman spectroscopy, Mater. Sci. 26 (2008) 433-441. https://doi.org/10.1016/j.carbon.2011.01.059.

[57] T. Batakliev, I. Petrova-Doycheva, V. Angelov, V. Georgiev, E. Ivanov, R. Kotsilkova, M. Casa, C. Cirillo, R. Adami, M. Sarno, P. Ciambelli, Effects of Graphene Nanoplatelets and Multiwall Carbon Nanotubes on the Structure and Mechanical Properties of Poly(lactic acid) Composites: A Comparative Study, Appl. Sci. 9 (2019) 469. https://doi.org/10.3390/app9030469.

[58] S. Abelló, D. Montané, Exploring iron-based multifunctional catalysts for fischertropsch synthesis: A review, ChemSusChem. 4 (2011) 1538-1556. https://doi.org/10.1002/cssc.201100189.

[59] D. Shi, Q. Yang, C. Peterson, A.F. Lamic-Humblot, J.S. Girardon, A. GribovalConstant, L. Stievano, M.T. Sougrati, V. Briois, P.A.J. Bagot, R. Wojcieszak, S. Paul, E. Marceau, Bimetallic $\mathrm{Fe}-\mathrm{Ni} / \mathrm{SiO}_{2}$ catalysts for furfural hydrogenation: Identification of the interplay between $\mathrm{Fe}$ and $\mathrm{Ni}$ during deposition-precipitation and thermal 
treatments, $\quad$ Catal. $\quad$ Today. $\quad 334 \quad$ (2019) 162-172. https://doi.org/10.1016/j.cattod.2018.11.041.

[60] Y. Liu, J.F. Chen, Y. Zhang, Effects of pretreatment on iron-based catalysts for forming light olefins via Fischer-Tropsch synthesis, React. Kinet. Mech. Catal. 114 (2015) 433-449. https://doi.org/10.1007/s11144-014-0821-0.

[61] H. Yue, Y. Zhao, S. Zhao, B. Wang, X. Ma, J. Gong, A copper-phyllosilicate coresheath nanoreactor for carbon-oxygen hydrogenolysis reactions, Nat. Commun. 4 (2013) 1-7. https://doi.org/10.1038/ncomms3339.

[62] J. Morales, J.P. Espinos, A. Caballero, A.R. Gonzalez-Elipe, J.A. Mejias, XPS study of interface and ligand effects in supported $\mathrm{Cu}_{2} \mathrm{O}$ and $\mathrm{CuO}$ nanometric particles, $\mathrm{J}$. Phys. Chem. B. 109 (2005) 7758-7765. https://doi.org/10.1021/jp0453055.

[63] L. Jian, J. Xiuling, C. Dairong, L. Wei, Solvothermal synthesis and characterization of $\mathrm{Fe}_{3} \mathrm{O}_{4}$ and $\gamma-\mathrm{Fe}_{2} \mathrm{O}_{3}$ nanoplates, J. Phys. Chem. C. 113 (2009) 4012-4017. https://doi.org/10.1021/jp810583e.

[64] J.F. Moulder, W.F. Stickle, P. E.'Sobol, K.D. Bomben, Handbook of X-ray Photoelectron Spectroscopy: A Reference Book of Standard Spectra for Identification and Interpretation of XPS Data, Physical Electronics Division, Perkin-Elmer Corporation, Minnesota, 1992.

[65] Q. He, X. Yang, X. Ren, B.E. Koel, N. Ramaswamy, S. Mukerjee, R. Kostecki, A novel $\mathrm{CuFe}$-based catalyst for the oxygen reduction reaction in alkaline media, $\mathrm{J}$. $\begin{array}{lllll}\text { Power } & \text { Sources. } & 196 & \text { (2011) }\end{array}$ https://doi.org/10.1016/j.jpowsour.2011.04.016.

[66] M.C. Biesinger, Advanced analysis of copper X-ray photoelectron spectra, Surf. Interface Anal. 49 (2017) 1325-1334. https://doi.org/10.1002/sia.6239. 
[67] Z. Yang, S. Guo, X. Pan, J. Wang, X. Bao, FeN nanoparticles confined in carbon nanotubes for CO hydrogenation, Energy Environ. Sci. 4 (2011) 4500-4503. https://doi.org/10.1039/c1ee01428e.

[68] X. Chen, D. Deng, X. Pan, X. Bao, Iron catalyst encapsulated in carbon nanotubes for CO hydrogenation to light olefins, Chinese J. Catal. 36 (2015) 1631-1637. https://doi.org/10.1016/S1872-2067(15)60882-8.

[69] M.C. Bahome, L.L. Jewell, D. Hildebrandt, D. Glasser, N.J. Coville, Fischer-Tropsch synthesis over iron catalysts supported on carbon nanotubes, Appl. Catal. A Gen. 287 (2005) 60-67. https://doi.org/10.1016/j.apcata.2005.03.029.

[70] K. Cheng, V. V. Ordomsky, B. Legras, M. Virginie, S. Paul, Y. Wang, A.Y. Khodakov, Sodium-promoted iron catalysts prepared on different supports for high temperature Fischer-Tropsch synthesis, Appl. Catal. A Gen. 502 (2015) 204-214. https://doi.org/10.1016/j.apcata.2015.06.010.

[71] H.M.T. Galvis, J.H. Bitter, C.B. Khare, M. Ruitenbeek, A.I. Dugulan, K.P. de Jong, Supported Iron Nanoparticles as Catalysts for Sustainable Production of Lower $\begin{array}{lllll}\text { Olefins, } & \text { Science } & (80-. & \end{array} \quad$ 835-838. https://doi.org/10.1126/science.1215614.

[72] J.B. Butt, Carbide phases on iron-based Fischer-Tropsch synthesis catalysts part I: Characterization studies, Catal. Letters. 7 (1991) 61-81. https://doi.org/10.1007/BF00764492.

[73] C. Yang, H. Zhao, Y. Hou, D. Ma, $\mathrm{Fe}_{5} \mathrm{C}_{2}$ Nanoparticles: A Facile Bromide-Induced Synthesis and as an Active Phase for Fischer-Tropsch Synthesis, J. Am. Chem. Soc. 134 (2012) 15814-15821. https://doi.org/10.1021/ja305048p.

[74] M.D. Shroff, D.S. Kalakkad, K.E. Coulter, S.D. Kohler, M.S. Harrington, N.B. 
Jackson, A.G. Sault, A.K. Datye, Activation of Precipitated Iron Fischer-Tropsch $\begin{array}{llllll}\text { Synthesis } & \text { Catalysts, } & \text { J. } & \text { Catal. } & 156 & \text { (1995) }\end{array}$ https://doi.org/10.1006/jcat.1995.1247.

[75] M.C. Biesinger, L.W.M. Lau, A.R. Gerson, R.S.C. Smart, Resolving surface chemical states in XPS analysis of first row transition metals, oxides and hydroxides: Sc, Ti, V, $\mathrm{Cu}$ and Zn, Appl. Surf. Sci. $257 \quad$ (2010) 887-898. https://doi.org/10.1016/j.apsusc.2010.07.086.

[76] F. Banhart, Interactions between metals and carbon nanotubes: At the interface between old and new materials, Nanoscale. 1 (2009) 201-213. https://doi.org/10.1039/b9nr00127a.

[77] L. Yu, W.X. Li, X. Pan, X. Bao, In- and out-dependent interactions of iron with carbon nanotubes, J. Phys. Chem. C. $116 \quad$ (2012) 16461-16466. https://doi.org/10.1021/jp302311r.

[78] M. Al-Dossary, J.L.G. Fierro, J.J. Spivey, Cu-promoted $\mathrm{Fe}_{2} \mathrm{O}_{3} / \mathrm{MgO}$-based FischerTropsch catalysts of biomass-derived syngas, Ind. Eng. Chem. Res. 54 (2015) 911921. https://doi.org/10.1021/ie504473a.

[79] Y. Lu, R. Zhang, B. Cao, B. Ge, F.F. Tao, J. Shan, L. Nguyen, Z. Bao, T. Wu, J.W. Pote, B. Wang, F. Yu, Elucidating the Copper-Hägg Iron Carbide Synergistic Interactions for Selective CO Hydrogenation to Higher Alcohols, ACS Catal. 7 (2017) 5500-5512. https://doi.org/10.1021/acscatal.7b01469. 